DIW BERLIN

Discussion

Papers
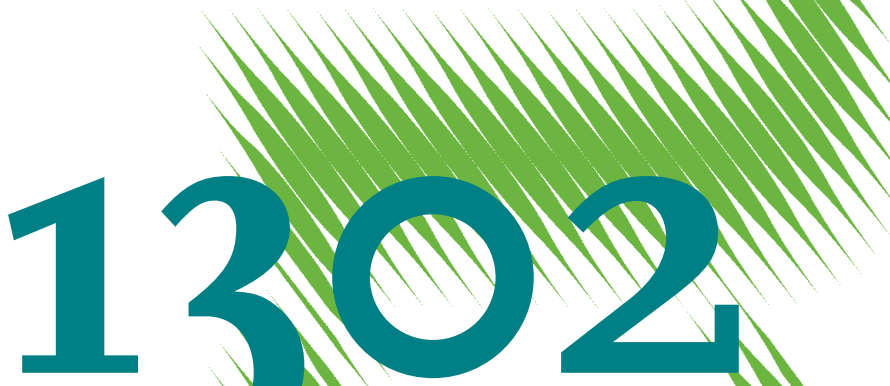

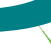
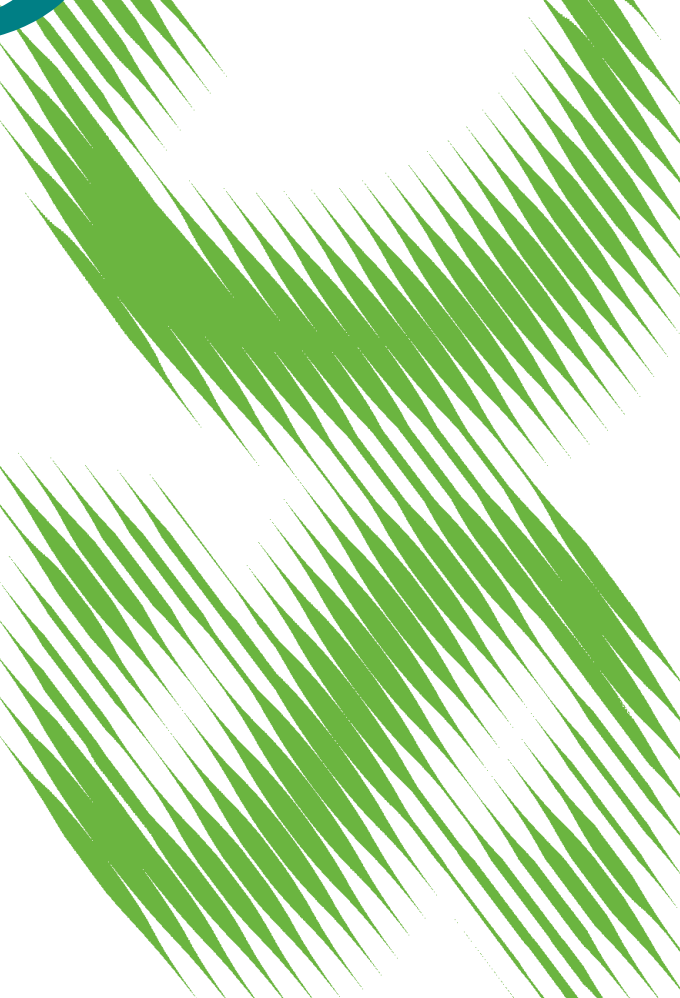

Oil Prices, Exchange Rates and Asset Prices 
Opinions expressed in this paper are those of the author(s) and do not necessarily reflect views of the institute.

IMPRESSUM

(C) DIW Berlin, 2013

DIW Berlin

German Institute for Economic Research

Mohrenstr. 58

10117 Berlin

Tel. $+49(30) 89789-0$

Fax +49 (30) $89789-200$

http://www.diw.de

ISSN print edition $1433-0210$

ISSN electronic edition 1619-4535

Papers can be downloaded free of charge from the DIW Berlin website:

http://www.diw.de/discussionpapers

Discussion Papers of DIW Berlin are indexed in RePEc and SSRN:

http://ideas.repec.org/s/diw/diwwpp.html

http://www.ssrn.com/link/DIW-Berlin-German-Inst-Econ-Res.html 


\title{
Oil Prices, Exchange Rates and Asset Prices
}

\section{Marcel Fratzscher ${ }^{1}$, Daniel Schneider ${ }^{2}$ and Ine Van Robays ${ }^{3}$}

May 2013

\begin{abstract}
This paper takes a financial market perspective in examining the relationship between oil prices, the US dollar and asset prices, and it exploits the heteroskedasticity for the identification of causality in a multifactor model. It finds a bidirectional causality between the US dollar and oil prices since the early 2000s. Moreover, both oil prices and the US dollar are significantly affected by changes in equity market returns and risk. By contrast, oil prices did not react to changes in these financial assets before 2001. The paper provides evidence that this may be explained by the increased use of oil as a financial asset over the past decade, which intensified the link between oil and other assets. The model can account well for the strong and rising negative correlation between oil prices and the US dollar since the early 2000s, with risk shocks and the financialisation process of oil prices explaining most of the strengthening of this correlation.
\end{abstract}

JEL code: F30; G15.

Keywords: oil prices; asset prices; exchange rates; US dollar; identification; time-varying correlation.

\footnotetext{
${ }^{1}$ DIW Berlin, Humboldt-University Berlin and CEPR.

${ }^{2}$ Goethe University Frankfurt.

${ }^{3}$ Corresponding author, European Central Bank, Kaiserstraße 29, D-60311 Frankfurt am Main. E-mail: ine.vanrobays@ecb.europa.eu. The views expressed in this paper are solely those of the authors and cannot be attributed to the European Central Bank or the Eurosystem. Without implicating, we would like to thank Deepa Dhume Datta, Marco Lombardi, Ron Alquist and the participants of the ECB Monetary Policy and Commodity Prices Workshop for their helpful comments and suggestions.
} 


\section{Introduction}

The sharp increase in oil prices and oil price volatility over the past decade has coincided with a closer link between oil prices and asset prices, including exchange rates. One intriguing and wellknown example is the strong negative correlation between spot oil prices and the US dollar exchange rate since the early 2000s (see Figure 1), while there was no such systematic correlation over the previous three decades.

What explains the relationship between oil prices and asset prices, and this apparent structural change in the link? Has oil itself become a financial asset, in that its price reacts to and influences other assets in financial markets? And is this linked to the often-mentioned, yet elusive financialisation of oil? These are important questions for understanding the dynamics of oil prices, and ones the paper attempts to address from a financial market perspective.

There is a growing literature analyzing the link between oil prices and individual markets for financial assets. There is evidence, for instance, that oil prices affect individual asset prices at a monthly data frequency, such as US stock markets (Killian and Park 2009). And there is an intriguing link between oil prices and exchange rates, with Chen, Rogoff and Rossi (2009) showing that currency values of commodity exporters contain information about future commodity price movements, while commodity prices also have predictive power for commodity currencies, at least at high data frequencies (Ferrero, Rogoff and Rossi 2012). ${ }^{4}$

The present paper intends to contribute to and differs from this literature in two important ways. The first is methodological, with our approach allowing us to identify the multi-directional, contemporaneous causality between oil prices and asset prices. Identification of causality in the shock transmission is a key difficulty because asset prices simultaneously react to each other, as well as to changes in other observable and unobservable factors. This means that in simultaneous equation models of asset prices, restrictions on the interactions between the variables may be arbitrary and hard to justify. We solve the identification issue by exploiting the heteroskedasticity in daily asset prices, following the approach of Sentana and Fiorentini (2001) and Rigobon (2003). In essence, this methodology implies modeling each asset price within a multifactor model, and then to exploit the underlying heteroskedasticity to identify shocks specific to each asset price and the oil price in order to estimate the shock transmission.

Since Rigobon's (2003) seminal work, identification through heteroskedasticity (IH) has been widely used in the literature to analyze comovements between asset prices. Importantly, much of this work shows the advantages of the $\mathrm{IH}$ approach over alternative approaches, such as based on sign restrictions or a Cholesky decomposition, for identification especially when using higher-frequency

\footnotetext{
${ }^{4}$ On the link between oil prices and exchange rates, most of the literature has focused on analyzing one-way causality relying on non-structural econometric techniques, using monthly or quarterly data (see e.g. Amano and van Norden 1998, Chaudhuri and Daniel 1998, Bénassy-Quéré et al. 2007, Coudert et al. 2008, and Chen and Chen 2007, Razgallah and Smimou 2011, Yousefi and Wirjanto 2003, Zhang et al 2008 and Huang and Tseng 2010). Two papers focusing specifically on the high-frequency link between oil prices and exchange rates are Grisse (2010) and Weber (2012). However, their focus is much narrower on this bilateral link.
} 
financial market data. For example, Rigobon and Sack $(2003,2004)$ employ it to model the interaction between US monetary policy shocks and asset prices and more recently, Bouakez and Normandin (2010) for the impact of monetary policy on exchange rates. Gravelle, Kichian and Morley (2006) rely on identification through heteroskedasticity to detect changes in the structural transmission of common shocks to cross-country assets prices. Anderson, Bollerslev, Diebold and Vega (2007) apply this methodology to evaluate the effects of macroeconomic news on global stock, bond and foreign exchange rates, and Ehrmann et al. (2010) for the transmission of asset price shocks between the US and the euro area.

The second difference and intended contribution of the paper is that it models the oil price in a multi-asset price framework, rather than via-a-vis an individual asset market. Specifically, in addition to the oil price, our model includes the effective US dollar exchange rate (for the term of trade of the US economy), US equity returns (as a measure of demand and economic activity), the US short-term interest rate (as a proxy for monetary policy conditions), the VIX (for risk or risk aversion) and the open interest in the oil futures market, i.e. the number of open futures contracts (as a proxy for the financialisation of the oil market). Importantly, the methodology allows us not only to estimate the direct transmission of shocks across pairs of assets, but also enables us to identify the indirect transmission channels via third asset markets. Empirically, these indirect channels turn out to be important.

As to the empirical findings, a first central issue is whether the oil price is an asset price in that it reacts to other financial assets reflecting future economic and financial fundamentals. We confirm the findings of Killian and Vega (2011) that oil prices generally do not respond to US macroeconomic news, while other asset prices do. Yet oil immediately reflects changes in other financial assets, indicating that oil is a truly global commodity whose price is driven by US-specific factors just as much as by global economic and financial factors that are captured by various asset prices.

More specifically, our results find causality between exchange rates and oil prices that runs in both directions; a $10 \%$ increase in the price of oil leads to a depreciation of the US dollar effective exchange rate by $0.28 \%$ on impact, whilst a weakening of the US dollar by $1 \%$ causes oil prices to rise by $0.73 \%$. This negative causality in both directions is intuitive from a number of perspectives. Since oil is priced in US dollars, a US dollar depreciation makes oil cheaper in domestic currency terms for those countries not pegged to the US dollar, thus raising global oil demand and the price of oil. Similarly, oil exporters that largely have non-US dollar priced imports face budgetary pressures in response to a US dollar depreciation and thus may change their price setting and production to induce a rise in oil prices. Moreover, an exogenous rise in oil prices may induce a decline in the US dollar if it affects relatively more strongly oil-intensive countries such as the US, or leads to a stronger petro-dollar recycling into important demand of goods and services from other regions such as Europe. Finally, as oil is expressed in dollars, it can be used as a hedge against a depreciation of the US dollar, thereby pushing up the demand for oil as a financial asset.

We find that oil prices as well as the US dollar exchange rate also respond significantly to other asset price shocks. Specifically, a $1 \%$ positive stock market shock increases oil prices by $0.7 \%$. An increase in risk and risk aversion (as proxied by the VIX) reduces oil prices but also leads to an appreciation of the US dollar, in line with the often-mentioned flight-to-safety phenomenon which entails a US 
dollar appreciation in periods of uncertainty and crises. Interestingly, a positive shock to financialisation of the oil markets (i.e. the number of open contracts) induces a rise in oil prices, which indicates that financialisation may indeed explain some of the rise in oil prices since early 2000 s when this phenomenon started to intensify.

The empirical estimates show that there is a sizeable difference in the strength of transmission between direct and indirect transmission channels. For instance, we find no direct effect of equity market shocks on oil prices, but a sizeable and significant overall effect via the effect of equity market shocks on interest rates and risk. Similarly, the overall effects of risk shocks on oil prices and on the US dollar are stronger than the direct effects due to indirect transmission channels of risk via interest rates and stock markets. This result is important as it suggests that the transmission of shocks in financial markets to and from oil prices is not uni-directional and limited to individual asset prices, but that the transmission process is complex and occurs often indirectly via third asset markets.

In terms of economic significance, the variance decomposition indicates that between $11 \%$ and $25 \%$ of the variation in oil prices and in exchange rates since 2001 can be explained by shocks to other asset prices. Overall, however, shocks to individual asset prices explain only a limited fraction of other asset prices. Risk shocks generally are the most important determinant of asset price and oil price movements over our sample and account for close to $13 \%$ of the variation in oil prices and in the US dollar exchange rate during volatile periods, such as the 2008-09 global financial crisis.

Remarkably, this behavior of oil as a financial asset - in that it immediately reflects information of other asset prices - was largely absent before the early 2000s. The daily direct causal link between oil prices and exchange rates disappears when using data before 2001, and the importance of equity return and risk shocks in explaining daily oil price movements declines considerably. This changed behavior of oil prices might be explained by the increased use of oil as a financial asset since the early 2000s. In line with this hypothesis, we find that shocks to open interest in the oil futures market only affected oil prices after 2001, which is exactly the period in which the oil market became increasingly 'financialized'.

Finally, turning back to the negative correlation between oil prices and the US dollar, as shown in Figure 1, we show that the financialisation process is partly responsible for explaining the intensification over time. Overall, our model can account well for the dynamics and the level shift of this correlation: it is in particular oil and exchange rate shocks that explain the overall dynamics, whereas it is partly financialisation but mainly an increased dominance of risk shocks that explain the level shift (i.e. the strong increase in the negative correlation since 2000 and in particular since the start of the global financial crisis in 2007).

Nevertheless, a number of caveats should be stressed. First, our agnostic approach to analyzing the interaction between asset prices comes at the cost that the structural shocks are difficult to interpret. Yet evaluating whether the estimated structural shocks display increased volatility in the periods that we would expect provides us some intuition for interpreting the shocks. Second, although our use of the number of open contracts is fairly standard in the literature, any measure of the financialisation of oil markets is necessarily imprecise. We therefore consider the findings for financialisation only as suggestive. Finally, in our framework, it is difficult to get at the functioning of 
the underlying channels, e.g. between oil prices and exchange rates. Accordingly, in all instances, the empirical estimates show the overall relationship across various asset prices, while necessarily abstracting from the specific functioning of the channels.

The paper is organized as follows. The next section discusses the issue of endogeneity between oil, the exchange rates and other asset prices. Section 3 describes the methodology and the data: first we discuss the identification problems that arise in simultaneous equation models, then we explain how identification through heteroskedasticity can overcome these issues, and finally we provide some intuition behind the identified structural shocks. The empirical results are outlined in Section 4 , followed by tests for robustness in Section 5. Section 6 concludes.

\section{Endogeneity between oil prices, exchange rates and asset prices}

A central hypothesis of the present paper is that the transmission of shocks from one financial asset to another may occur either directly or indirectly via other asset markets, and that this may apply also to oil prices and exchange rates. This section therefore outlines some of the channels through which shocks may be transmitted across markets, and what this should imply for the priors of our empirical analysis.

Focusing first on the link between oil prices and exchange rates, the difficulty in understanding their negative correlation, as shown in Figure 1, is that the causality can run in both directions. Two main channels of transmission through which changes in oil prices can affect exchange rates have been widely documented in the literature. ${ }^{5}$ The first channel is through the terms of trade. For oilimporting countries, an increase in oil prices will lead to a deterioration of the trade balance and subsequently to a depreciation of the local currency. In this light, Backus and Crucini (2000) show that the variation in oil prices even determines the most part of the variation in the terms of trade. Second, oil prices can also affect exchange rates via wealth effects. Krugman (1983) and Golub (1983) document that higher oil prices will transfer wealth from oil importers to oil exporters, which leads to a change in the exchange rate of the importing country through current account imbalances and portfolio reallocation. The final impact will depend on the dependence on oil and the share of exports to oil-exporting countries. More recent evidence on this effect can be found in Kilian et al. (2009) and Bodenstein et al. (2011), amongst others.

On the other hand, the negative correlation can arise because changes in the US dollar exchange rate negatively affect oil prices. More specifically, exchange rates can change oil prices via its effect on oil supply and oil demand, and via financial markets. ${ }^{6}$ First, on the supply side of the oil market, a depreciation of the US dollar might lead oil producers to limit oil supply and raise oil prices to stabilize the purchasing power value of their export revenues in dollars, see e.g. Yousefi and Wirjanto $(2003,2005)$ for evidence on this channel. Second, a depreciation of the dollar might also

\footnotetext{
${ }^{5}$ See e.g. Buetzer et al. (2012) for a more detailed explanation on these channels of transmission.

${ }^{6}$ See e.g. Breitenfellner and Cuaresma (2008) for more details on these channels.
} 
increase the demand for oil, as oil imports become cheaper in local currency for countries besides the US (De Schryder and Peersman 2012). Moreover, several countries such as China peg their currency to the US dollar. Dependent on their oil intensity, a depreciation could lead to an increase in oil demand driven by higher exports (Benassy-Quere et al. 2005).

Exchange rates can also affect oil prices directly through financial markets or indirectly via other financial assets, and through portfolio rebalancing and hedging practices in particular. A fall in the value of the US dollar will reduce the attractiveness of dollar-denominated assets and could thereby increase the demand for alternative investments such as oil. As oil prices are expressed in US dollars, oil futures may be a good hedge against an expected depreciation in the USD. The importance of this financial channel could have increased over time, as the volume of crude oil futures traded on NYMEX more than quintupled since the early 2000s - one specific hypothesis for which we show evidence in this paper. In contrast to the literature dealing with causality from oil prices to exchange rates, the empirical evidence on these reverse causality effects is relatively limited.

Turning next to the effect of other asset prices on oil prices and exchange rates, there is a sizeable literature analyzing the role of monetary policy. As many observers argued that the negative correlation between exchange rates and oil prices could be driven by monetary policy, we include changes in the short-term money market interest rate as a proxy. Exchange rate models typically include interest rate changes based on the uncovered interest rate parity relationship and the finding that monetary policy effects on expectations matter for explaining exchange rate movements (Engle, Mark and West 2007). There is ample evidence for a delayed overshooting effect in that a tightening shock appreciates a currency on impact and subsequently gradually depreciates the exchange rate in line with uncovered interest parity (see e.g. Scholl and Uhlig 2009). Concerning oil prices, several authors have pointed towards low interest rates as an important driver of high real commodity prices over the past years (Frankel 2008).

For equity markets, there is evidence that higher oil prices lower US stock markets, and that this effect mainly materializes through a demand channel (Killian and Park 2009). For the reverse effect, a positive equity market shock - as it reflects, at least in part, higher expected earnings and growth of listed firms - entails more economic activity and more demand, and in turn raises the price of oil. Demand shocks have indeed been widely held responsible for the evolution in oil prices since 2003 as strong emerging economy commodity demand growth pushed oil prices upwards (Hamilton 2009, Kilian 2009, Lombardi and Van Robays 2011). Related to this, one explanation of the negative correlation between exchange rates and oil prices could exactly be the strong demand growth in China, which lifted oil prices upwards and at the same time was associated with a weaker US dollar to which the Renminbi is pegged.

For risk and risk aversion, there has been compelling evidence that a rise in financial market risk which has been shown to be closely linked to uncertainty and risk aversion (Bekaert, Hoerova and Lo Duca 2012) - generally induces an appreciation of the US dollar as US financial assets are perceived as safe and liquid, triggering what has been referred to as a flight-to-safety phenomenon (see e.g. Fratzscher 2009). By contrast, in particular EME currencies depreciate during periods of heightened risk and investors withdraw capital from these countries. By contrast, a rise in risk and uncertainty might lower oil prices as economic activity slows down and investors shift into relatively safer 
financial assets during such periods. In addition, oil price volatility has been shown to increase in period of increased uncertainty (Van Robays 2012).

Finally, there is a large literature that analyses the interaction across other financial asset classes. One dominant focus has been in particular the interaction between monetary policy and equity markets. The seminal contributions by Rigobon and Sack $(2003,2004)$ and Bernanke and Kuttner (2004) show that the causality runs in both directions, with a tightening monetary policy shock lowering equity markets - most findings in the literature indicate that a tightening shock of 100 b.p. in US monetary policy drives US equity markets lower by $4-6 \%$. By contrast, higher equity markets tend to raise short-term interest rates and make a monetary policy tightening more likely as higher stock markets tend to be associated with higher economic activity and more inflationary pressure. Ehrmann et al. (2010) model money markets, equity markets, and bond markets in the US and euro area and confirm not only these cross-market linkages but also a cross-country transmission process, with the US tending to be the dominant country in the transmission process of financial market shocks.

\section{Estimation methodology and data}

In this section, we first describe the model set-up, the data used and the structural break test. We then discuss the problem of identification that arises in simultaneous equation models and how identification through heteroskedasticity provides a solution. Finally, we briefly explain the estimation procedure and the interpretation of the shocks.

\subsection{Model specification and data}

To assess the interlinkages between exchange rates, oil prices and other asset prices we rely on a structural six-variable VAR model that models the evolution of the endogenous variables as dependent on their own current and past values, current and past values of other endogenous variables, exogenous variables and an error term. As outlined in the previous section, we include the effective dollar exchange rate, oil prices, as well as US stock returns, US short-term interest rates, a proxy for risk and a proxy for the financialisation of oil markets. ${ }^{7}$

Accordingly, the six-variable VAR model looks as follows:

$$
A y_{t}=\tilde{c}+\tilde{A}_{1} y_{t-1}+\cdots+\tilde{A}_{p} y_{p-1}+\tilde{\Gamma} x_{t}+\varepsilon_{t}
$$

with $y_{t}$ a six-element vector of endogenous variables, $A$ the contemporaneous impact matrix, $\tilde{c}$ a vector of constants, $\tilde{A}_{i}, i=1, \ldots, p$ and $\tilde{\Gamma}$ the coefficient matrices, and $\varepsilon_{t}$ the vector of structural error terms with diagonal variance matrix $\Sigma_{\varepsilon}=E\left(\varepsilon_{t} \varepsilon_{t}{ }^{\prime}\right)$. The vector $x_{t}$ captures the exogenous

\footnotetext{
${ }^{7}$ In order to be consistent with the choice of the US dollar for the exchange rate, we include US-specific interest rates, stock returns and financial market risk. One option is to use global variables instead, or to complement the model with global variables. Extending the model much beyond the six-variable VAR is however computationally difficult.
} 
variables, such as the macroeconomic news. In this paper, the $A$ matrix is of main interest as its offdiagonal elements capture the contemporaneous impact across the endogenous variables.

We estimate the model using daily data over a sample period from 1 January 2001 until 19 October 2012. We use as endogenous variables the log nominal effective US dollar exchange rate for the exchange rate, the log nominal WTI crude oil price expressed in US dollars for the oil price, the log Dow Jones Industrial Average Index as stock price index, the three-month Certificate of Deposit interest rate as the short rate, and the Chicago Board Options Exchange Market Volatility Index (VIX) as the measure of risk. As a proxy for the financialization of the oil futures market, we include weekly open interest in the NYMEX oil futures market gathered by the Commodities Futures Trading Commission (CFTC), which we linearly interpolate to obtain data at a daily frequency. Open interest is the total number of futures contracts that are not closed or delivered on a particular day, and is therefore a measure of the use of paper oil as a financial asset. ${ }^{8}$ To account for non-stationarity in the data, we estimate the model in first differences, and we include two lags for the endogenous variables based on the conventional selection criteria. ${ }^{9}$ All series except for the effective exchange rate are sampled at NYSE closing time. In order to limit any possible bias in the results coming from differences in timing, we construct our own nominal effective USD exchange rate index using New York closing rates. ${ }^{10}$

Finally, we augment the model with macroeconomic news to account for any unexpected changes related to the macroeconomy. Andersen et al. (2003) show that macroeconomic news create jumps at high frequencies in the US dollar spot exchange rate, which is also found in Faust et al. (2007), amongst others. Ferraro et al. (2009), in contrast, find that macroeconomic news components do not improve the exchange rate forecast in a model in which oil prices are already included. They relate their findings to the results reported in Kilian and Vega (2011), who show that macroeconomic news announcements also do not contemporaneously predict oil prices. Similar to Andersen et al. (2007) and Ehrmann et al. (2011), we include the unexpected component of a set of US variables that are measured as the difference between the expectations and the actual announcements.

As is common in the announcement literature, the set of US variables includes news releases on the NAPM/ISM index of purchasing managers and consumer confidence, GDP, industrial production, retail sales, trade balance figures, average weekly hours worked, non-farm payrolls employment and unemployment, housing start figures, and CPI as well as PPI releases. Moreover, monetary policy news - i.e. the surprise components of Fed decisions on FOMC meeting days - are included in order

\footnotetext{
${ }^{8}$ It is important to stress that we do not aim at measuring speculation in the oil futures market, but instead want to assess the effect of an increased use of oil as a financial asset. Changes in open interest can be driven by commercials, noncommercials, hedgers and speculators, and we do not distinguish between their actions.

${ }^{9}$ Specifying all endogenous variables in first differences makes the VAR model stable, i.e. all eigenvalues of the VAR companion matrix are well below one.

${ }^{10}$ The effective exchange rate is constructed as weighted average of the bilateral USD currencies of Australia, Canada, euro area, Japan, Sweden, Switzerland and United Kingdom. The weights for the index are those from the major currency index of the FRB H.10 release.
} 
to capture identified, exogenous US monetary policy shocks (see e.g. Bernanke and Kuttner 2005, Ehrmann and Fratzscher 2007). Expectations data stem from Bloomberg surveys and are the mean across 40-50 financial market participants, taken a few days before respective data releases or FOMC meetings. Note that there is usually only one data release per variable per month, which implies that such macroeconomic news shocks only capture a small fraction of the overall changes in the variables and their underlying expectations. However, the advantage of these news shocks is that they allow for a clean identification of important macro and monetary policy shocks.

While our model is flexible with respect to changes in volatility, it maintains the standard structural VAR assumption of constant slope parameters which may become questionable in long samples. In particular, the changing nature of the oil-exchange rate correlation over time suggests the necessity for testing the presence of structural breaks in the equations of these two variables. A natural starting point for such an examination is the period around 2000 when the correlation between oil prices and the dollar started its negative trend. This is corroborated by the findings in Chen et al. (2010) who apply the Andrews (1993) test for parameter instability to quarterly Granger causality regressions involving the oil price and bilateral US dollar exchange rates. They report strong evidence for structural breaks in early 2000. In order to examine our high-frequency data for structural breaks, we also follow the Andrews (1993) procedure and calculate the Chow-type heteroskedasticity-robust Wald-statistic for each day over our sample period. The test statistics are calculated based on the equations for the oil price and the exchange rate as they appear in our reduced-form VAR.

Our results confirm the findings in Chen et al. (2010). We find significant evidence for structural breaks in both equations. While the Chow statistics based on the oil price equation show an elevated level between 2001 and mid-2003, the same statement holds true for the exchange rate equation for the period from mid-1998 to mid-2001. Given the evidence in favor of structural breaks we split our sample in two parts in order to account for time-variations in the slope parameters. We pick January 2001 as our sample split date, as this choice lies in the overlap of the two periods mentioned above.

\subsection{Identification through heteroskedasticity}

In order to estimate the structural VAR model of (1), we need to transform the model by premultiplying both sides of the structural VAR by $A^{-1}$ :

$$
y_{t}=A^{-1} \tilde{c}+A^{-1} \widetilde{\mathrm{A}}_{1} y_{t-1}+\cdots+A^{-1} \widetilde{\mathrm{A}}_{p} y_{t-p}+A^{-1} \widetilde{\Gamma} z_{t}+A^{-1} \varepsilon_{t}
$$

and rewrite it as:

$$
y_{t}=c+A_{1} y_{t-1}+\cdots+A_{p} y_{p-1}+\Gamma x_{t}+u_{t}
$$

where $A_{i}=A^{-1} \tilde{A}_{i}, i=1, \ldots, p, \Gamma=A^{-1} \tilde{\Gamma}$. The vector of reduced-form shocks, $u_{t}=A^{-1} \varepsilon_{t}$ is related to the structural shocks through matrix $A$. The parameters of this reduced form equation, $A_{i}$, $u_{t}$ and $\Sigma_{u}$, can be consistently estimated by ordinary least squares (OLS). This implies that the coefficients in the structural model can be recovered if the contemporaneous impact matrix $A$ is identified. Hence, we need to make some assumptions on how to recover the elements of this $A$ matrix from the reduced form estimates. 
Using the information from (1)-(3), we can rewrite the variance of the reduced form errors as $\Sigma_{u}=A^{-1} \Sigma_{\varepsilon} A^{-1 \prime}$. The reduced form variance $\Sigma_{u}$ can be estimated via equation (3), which implies that $A$ can be recovered if the number of unknown parameters is not larger than the number of equations. This is however not the case, so additional information is needed to identify the model. In most of the structural VAR literature, additional restrictions are imposed in the form of zero restrictions or sign restrictions. ${ }^{11}$

However, as exchange rates, oil prices and asset prices react simultaneously to each other, imposing zero restrictions to identify the model is implausible, and long run restrictions are equally hard to justify. Sign restrictions, on the other hand, do allow for contemporaneous effects among the variables but constrain these to be of a particular sign. For the reason that there is no consensus in the literature yet on the significance or the sign of the bidirectional causality between oil prices and exchange rates (as well as for some other asset price relationships) on a daily frequency, this approach is not justifiable. The main aim of this paper is exactly to estimate the direction, significance, and magnitude of the contemporaneous linkage across oil prices, exchange rates and other asset prices, and none of the conventional methods of structural VAR model identification seems well suited for this.

To address these issues, we use a different approach that does not require us to restrict the elements in the $A$ matrix, but uses information from the heteroskedasticity that exists in the data. More specifically, we follow the identification through heteroskedasticity $(\mathrm{IH})$ methodology of Rigobon (2003). The intuition behind this approach is that, for example, a shift in the variance of oil shocks relative to exchange rates shocks affects the covariance between oil prices and exchange rates in a way that depends on the responsiveness of exchange rates to oil shocks. In other words, in a regime of higher oil price volatility, we obtain more information on the exchange rate response to oil shocks as oil shocks are more likely to occur, and vice versa. Each additional heteroskedastic regime adds more equations to the system than unknowns, which enables us to estimate the structural parameters we are interested in. In principle, two regimes are sufficient to identify the model. $^{12}$

The existence of heteroskedasticity solves the identification problem in our simultaneous equation model under two conditions. First, as is standardly assumed in the literature, the structural shocks should be uncorrelated. Second, although the magnitude of the shocks changes over time, a second assumption is that the contemporaneous impact matrix $A$ is stable. This is a common assumption imposed in ARCH or GARCH models for example. We provide a more detailed explanation on the methodology in the appendix.

Although identification through heteroskedasticity enables us to estimate the structural model without imposing implausible restrictions on the variables of interest, this generality comes at the cost that the structural shocks are harder to interpret and the model is only identified up to a

\footnotetext{
${ }^{11}$ Kilian (2012) provides a comprehensive survey of both established and newer identification methods for structural VARs, including identification through heteroskedasticity.

12 In a bivariate VAR, for example, we have three equations for four unknowns under the assumption of unconditional homoskedasticity. As the parameters are assumed to be stable, two different heteroskedastic regimes will add three equations for only two unknowns, which implies that the problem of identification can be solved.
} 
rotation of the $A$ matrix. To address the latter problem, we impose additional restrictions to help us to pick the rotation that represents the true underlying economic relationships. ${ }^{13}$ Following Rigobon and Sack (2004) and Ehrmann et al. (2010), we assume that an increase in short-term interest rates (which could be seen as a proxy for a monetary policy shock) leads to a decline in stock markets as it lowers the demand for goods and services. ${ }^{14}$ This fairly uncontroversial restriction is imposed on the corresponding structural parameter contained in the A matrix, and will help us to correctly identify the structural parameters without restricting the coefficients of main interest. Moreover, the estimations show that this restriction is not binding, and in contrast to the literature which typically imposes several additional restrictions, we manage to get plausible estimates with only imposing one. The problem of interpretation of the structural shocks is harder to tackle; we discuss this in more detail later on.

\subsection{Estimation procedure}

Before being able to estimate the model, we need to determine the different regimes for the variance covariance matrix of the reduced form shocks that provide the additional information we need to identify the model. First, we estimate the reduced form model and compute the residuals. Based on these residuals, we define five heteroskedastic regimes. The first one consists of observations where none of the residuals shows higher than normal volatility. The four other regimes are (i) a high oil volatility regime, (ii) a high exchange rate regime, (iii) a regime in which both the exchange rate and oil prices are volatile, and (iv) a regime in which all the variables included in the model have an increased variance. As there are many possible combinations of volatile variables, we re-map combinations that are close to our regimes to fit our classification. Observations with combinations that are hard to re-classify are excluded from estimation. ${ }^{15}$ Such a procedure is necessary to strike a balance between including sufficiently many observations in estimation and capturing the observed heteroskedasticity with only a few regimes, which has to be done for parameter parsimony. Periods of high volatility are defined as days on which the five-day rolling standard deviation of the residual is higher than 0.8 times the average standard deviation over the full sample. ${ }^{16}$

Table 1 shows the variance of the reduced-form shocks per identified regime together with the covariance between the exchange rates and oil prices. It is clear that this covariance fluctuates across different volatility periods, becoming more negative if e.g. the variance of oil prices and/or exchange rates is higher. This illustrates the idea behind identification through heteroskedasticity, i.e. a shift in the relative variance of the oil shock will affect the covariance between oil prices and exchange rates in a way that learns us more about the responsiveness of exchange rates to oil

\footnotetext{
${ }^{13}$ See Ehrmann et al. (2011) for more explanation on this.

${ }^{14}$ Based on the findings in Rigobon and Sack (2004), we choose the starting value for the rotations to be -7.00 for the impact interest rates on stock returns. We test for alternative starting values in the robustness section.

${ }^{15}$ For example, if the residuals from both the exchange rate and the interest rate equation are volatile, we count this as an observation for the exchange rate volatility regime. By contrast if the residuals from the interest rate and the stock price equation are volatile, the observation is excluded from the estimation sample. The full mapping of volatility combinations is available from the authors upon request.

${ }^{16}$ We test for the robustness of the results for a changed value of this threshold later on.
} 
shocks (cfr. Section 3.2).

Once the regimes are identified, we conduct the estimation and inference in a similar way as in Ehrmann et al. (2011). More specifically, we estimate the parameters by minimizing the following matrix norm:

$$
\begin{gathered}
\left\|g^{\prime} g\right\|=\sqrt{\operatorname{tr}\left[g^{\prime} g\right]}=\sqrt{\operatorname{vec}(g)^{\prime} \operatorname{vec}(g)} \text {, with } g=\sum_{i=1}^{5}\left[A \Sigma_{u, i} A^{\prime}-\Sigma_{\varepsilon, i}\right] \\
\text { s.t. } \Sigma_{i} \text { is diagonal and the direct effect on stock returns of an interest rate shock is positive }
\end{gathered}
$$

with $\Sigma_{\varepsilon, i}$ the variance of the structural shocks and $\Sigma_{u, i}$ the variance-covariance matrix of the reduced form shocks we estimate in each regime i. We rely on 200 bootstrap replications to generate the significance of our parameter estimates. For each of the regimes, we use the regime-specific covariance matrices to create new data with the same covariance structure in each of the replications. For each draw, we estimate the coefficients by minimizing the moments given by the restrictions, which allows us to generate $p$-values for the parameter estimates.

\subsection{Interpretation of the structural shocks}

A well-known disadvantage of using identification through heteroskedasticity is that the structural shocks are hard to define as the shocks are identified in a purely statistical way (see e.g. Kilian 2012). Recursive identification and identification through sign restrictions pin down the economic interpretations of the structural shocks by defining shocks as generating a particular set of responses that are determined in advance based on theory and underlying assumptions. In other words, for the reason that identification through heteroskedasticity does not impose restrictions on the impact response matrix, and we prefer to remain agnostic about the sign and magnitude of the interactions between the asset prices, the structural shocks are more difficult to interpret.

Herwartz and Lütkepohl (2011) propose different ways to give a more economical meaningful interpretation to the structural shocks identified using heteroskedasticity. First, if the impulse response functions using Cholesky or sign restrictions match those generated using identification though heteroskedasticity, then the interpretation of the structural shocks corresponds to that given in the Cholesky or sign restrictions approach (Lanne and Lütkepohl 2008, Lütkepohl and Netsunajev 2012). In our context, however, this is not feasible as we assume instantaneous feedback between asset prices, and plausibly disentangling six different shocks based on sign restrictions is far from straightforward. A second - albeit somewhat less conclusive - suggestion is to evaluate whether the identified shocks display increased volatility in the periods which one would expect based on the assumed interpretation of the shock. We follow the latter suggestion, and conclude that our identified shocks correspond well with the a-priori assumed interpretations.

First, we assume that the oil price and exchange rate equations are proxies for the markets' expectations concerning the evolution of both variables, and that the identified structural shocks in those equations correspond to exogenous oil and exchange rate shock respectively. Figure A.1 in the appendix shows the estimated daily structural shock series together with the 12-month rolling standard deviations. As is clear, the identified shocks in the oil price equation displays a higher volatility in March-May 2003 with the invasion of Iraq, in the summer of 2005 with hurricane Katrina, in the period surrounding the financial crisis and in the period of the Libyan oil production 
losses in early 2011 and the announcement of the Western embargo on Iranian oil production due to its nuclear program in early 2012. As none of the other structural shocks displays a similar pattern, it is likely that this shock correspond to an exogenous oil price shock. ${ }^{17}$

Second, as in Ehrmann et al. (2011), the stock price equation can be assumed to approximate changes in demand in the sense that a positive innovation in demand raises stock prices. Alternatively, variation in stock prices could also be driven by supply shocks such as changes in productivity. The structural shock in the VIX equation could be interpreted as shocks to risk, risk aversion or uncertainty. The rolling standard deviations of the stock market return and the VIX shocks are given in the second row of Figure A.1. Intuitively, both estimated structural shocks series display higher volatility in the period surrounding the financial crisis and the sovereign debt crisis in the euro area towards the end of our sample. In addition, the volatility of the stock market shocks was higher in the early 2000s related to the early millennium slowdown in growth in may industrialized countries and the stock market downturn in 2002, which in contrast is not well captured in the structural VIX shock series. Instead, in comparison with the stock market shocks, the identified VIX shocks concentrate around periods in which it is well-know that risk was elevated and uncertainty was high, i.e. the financial crisis and the euro area sovereign debt crisis.

Third, as is common in the literature, the interest rate equation might be interpreted as reflecting the expectations about the path of monetary policy, and the shock as a monetary policy shock (see e.g. Rigobon and Sack 2004). The identified interest rate shock in our model only shows elevated volatility in the period of the financial crisis, in which central banks drastically lowered rates. During the rest of the sample, the volatility in interest rates shocks is limited, which corresponds well with the concept of interest rate smoothing in a monetary policy reaction function. Finally, the rolling standard deviation of the shock to open interest indicates that these shocks mainly occurred in the beginning of our sample, in contrast to the other shocks. Intuitively, the large inflows in the oil futures market that led to the so-called financialization of the oil market mainly occurred in the early 2000s (CFTC 2008), which supports our interpretation of the open interest shock as a shock to financialization. In sum, the identified structural shocks each have a unique volatility pattern which helps us in giving the shocks some structural interpretation.

Evidently, these interpretations do not exclude alternative interpretations. Yet having a structural interpretation of the various shocks allows us to gauge whether the empirical estimates are sensible in terms of sign and size of the parameter estimates. Looking ahead at the results, many of the responses are indeed in line with prior expectations based on the assumed interpretation, and the loss in interpretation does not seem to outweigh the advantages of remaining agnostic about the interactions between oil, exchange rates and asset prices, as these are of main interest to this paper. Nevertheless, it is important to stress the possible caveats in interpreting the structural shocks.

\footnotetext{
${ }^{17}$ In contrast to most of the recent literature on oil, we do not disentangle oil demand shocks from oil supply shocks (see e.g. Kilian 2009 using Cholesky identification and Peersman and Van Robays 2009 using sign restrictions) as this requires data on oil production for which no valid proxy on a daily basis is readily available. Nevertheless, as we do control for several macroeconomic factors, we are more likely to filter out the endogenous part in the oil price shock of our model, and thereby capture exogenous oil supply shocks.
} 


\section{Empirical results}

This section discusses the empirical results. We start by describing the estimated direct and overall transmission effects after which we show the variance decompositions and the historical decompositions. We then discuss the issue of time variation in the correlation between oil prices and exchange rates and conclude with some tests of robustness.

\subsection{Direct and overall effects: causality between oil prices, exchange rates and other asset prices}

Table 2 shows the estimated direct and overall effects among the endogenous variables. The direct effects, shown in the upper part of the table, evaluate the multidirectional contemporaneous causality between oil prices and asset prices. In other words, these are the direct causal effects of the structural shocks (given in the columns) on the endogenous variables (given in the rows), keeping all other variables constant. Given the structural form equation (1), this corresponds to the $A$ matrix in $A Y_{t}=\ldots+\varepsilon_{t}$. The estimated overall effects are shown in the lower part of Table 2, and differ from the direct effects in the sense that they allow for a contemporaneous impact of the other variables as well. Given the reduced form model in equation (2), these overall effects correspond to the estimated parameters in the $A^{-1}$ matrix.

For ease of interpretation, we normalized the structural shocks to a one percent shock and we reversed the sign of the estimated parameters in the $A$ matrix. ${ }^{18}$ Following Ehrmann et al. (2011), we judge significance by the share of bootstrap estimates beyond zero. The significance levels at the 1-, 5-, and 10-percent level are shown by the number of stars in Table 2. We first focus on the bidirectional causality between oil prices and exchange rates, after which we discuss the reaction of both variables to other asset prices, and finally, the effects of shocks to oil prices and exchange rates themselves.

Concerning the link between oil prices and exchange rates, we find a significant causal direct effect that runs from oil prices to exchange rates and from exchange rates to oil prices. A $10 \%$ increase in the price of oil leads to a depreciation of the US dollar effective exchange rate with $0.28 \%$ on impact. On the other hand, a depreciation of the US dollar also causes oil prices to significantly rise; a decline in the value of the US dollar by $1 \%$ increases oil prices by $0.73 \%$. The overall effects between oil prices and exchange rates are very similar to the direct effects, suggesting that the transmission between oil prices and exchange rates mainly goes through the direct causal link. These results are in line with Grisse (2010) who also finds that the causality runs in both directions.

An intriguing result is that a positive shock to the financialisation of the oil markets (the number of open-interest contracts) induces a rise in oil prices. This finding seems to confirm that financialisation may indeed explain some of the rise in oil prices since the early 2000s when this phenomenon started to intensify. This result is in line with Sockin and Xiong (2012) who show that

\footnotetext{
${ }^{18}$ Given that $A Y_{t}=\cdots+\varepsilon_{t}$, the signs of the original estimates should be reversed in order to get the responses of the endogenous variables in the $Y_{t}$ matrix to the structural shocks captured in $\varepsilon_{t}$.
} 
financial trader positions can affect spot oil prices through their effect on oil demand. As expected, a shock in open interest only affects oil prices. Although we have to underline the possible caveats, this finding seems to point towards an increased role of oil as a financial asset. ${ }^{19}$ In the next section, we will evaluate the importance of this effect in driving oil prices, and evaluate whether this financialisation process can be held responsible for the changed co-movement between oil prices and exchange rates.

Moreover, we find that oil prices as well as the US dollar exchange rate respond significantly to other asset price shocks. A positive stock market shock of $1 \%$ increases oil prices by $0.7 \%$ which corresponds well with its interpretation of a demand shock. Interestingly, we find no direct effect of equity market shocks on oil prices, but a sizeable and significant overall effect via the effect of equity market shocks on interest rates and the VIX. Positive stock market shocks lower the exchange rate, which might be explained by the fact that over our sample, growth in the rest of the world and in emerging economies in particular was driving US stock markets upwards given the strong correlation with global stock markets. An increase in risk and risk aversion (as proxied by the VIX) reduces oil prices but also leads to an appreciation of the US dollar, in line with the often-mentioned flight-to-safety phenomenon which entails a US dollar appreciation in periods of uncertainty and crises (Fratzscher 2009). Again, the overall effects of risk shocks on oil prices and the US dollar are stronger than the direct effects due to indirect transmission channels of risk via interest rates and stock markets. By contrast, we do not find a statistically significant relationship between interest rates and oil prices. Except for the bidirectional causal link between oil prices and exchange rates, we find no strong effects of oil shocks and exchange rate shocks on other asset prices. ${ }^{20}$

These results have three important implications. First, oil prices significantly react to changes in other asset prices on a daily basis, which hints at the role of oil as a financial asset in the sense that it immediately responds to information captured in other assets. Second, the sizeable differences in the strength of transmission between direct and indirect transmission channels suggest that the transmission of shocks in financial markets to and from oil prices is not uni-directional and limited to individual asset prices. Instead, the transmission process is complex and occurs often indirectly via third asset markets. Finally, concerning the negative correlation between oil prices and exchange rates, almost all the shocks seem to drive oil prices and exchange rates in opposite directions (see the lower part of Table 2). Interestingly, this implies that the negative correlation might be explained by stock market shocks, risk shocks and open interest shocks, in addition to shocks in the exchange rate and oil. The historical decomposition of this correlation in the next section will investigate this further.

The finding that oil prices react to other asset prices is interesting in light of the results of Kilian and Vega (2011). They conclude that oil is not an asset price as oil prices do not respond to macroeconomic news,

\footnotetext{
${ }^{19}$ Note that this result does not say anything on the effect of speculation, as we only evaluate whether the increased use of the oil futures market had an effect on the oil price, independent on whether this increased use is driven by commercial, non-commercial traders, hedgers or speculators.

${ }^{20}$ Although its sign is not significant, the finding that stock market returns tend to be lower following an oil shock indicates that we might be capturing oil supply shocks more closely, as demand shocks should be associated with increases in stock returns (Kilian and Park 2007). This is also consistent with the fact that, as we control for macroeconomic factors, we are more likely to filter out the endogenous part in the oil price shock of our model, and thereby capture exogenous oil supply shocks.
} 
whereas other assets do. Table 3 shows our estimates of the relevance of the individual macroeconomic news components for the different variables in our model, as well as the F-statistic that tests for their joint significance. Generally, we can confirm the results of Kilian and Vega (2011), i.e. oil prices do not react to macroeconomic news whereas other assets such as exchange rates clearly do. However, our results show that oil prices, although they do not react to news, do instantaneously respond to information in other asset prices. In that sense, oil is a truly global commodity whose price is driven by US-specific factors just as much as by global economic and financial factors that are captured by various asset prices.

\subsection{Variance decompositions}

So far, we have shown that oil prices contemporaneously react to financial asset price shocks. To evaluate the economic significance, we generate one-day-ahead forecast error variance decompositions which are displayed in Table 4. These decompositions give the percentage contribution of a specific shock in explaining the variability of a specific variable. Panel A displays the weighted average across regimes, with the number of observations in each volatility regimes used as weights. Panel B shows the variance decomposition for the regime in which the variance of all variables is elevated, which corresponds to the period surrounding the financial crisis.

On average, about 16 percent of the variability in oil prices is explained by asset price shocks. Shocks to the exchange rate account for a limited 3 percent of the forecast error decomposition of oil prices. Conversely, about 11 percent of the exchange rate fluctuations is driven by other variables in our model, of which oil shocks explain a small 2 percent. This implies that, despite a causal direct link between oil prices and exchange rates, the steep rise in oil prices over the past decade is not explained by the strong depreciation of the US dollar over the same period, and vice versa. Instead, shocks in the stock market and the VIX are economically more relevant as their combined contribution to oil prices and exchange rates adds up to around 10 percent.

In general, however, shocks to individual asset prices explain only a limited fraction of other asset prices. Nevertheless, risk shocks are generally an important determinant of asset price and oil price movements, together with stock market shocks. Markedly, the contribution of risk shocks might even double during volatile periods, such as during the 2008-09 global financial crisis (see panel B of Table 4). The contribution of the risk shock to oil prices and exchange rates increases from $6.3 \%$ and $5.3 \%$ to $13.8 \%$ and $13.3 \%$ respectively. ${ }^{21}$ Also the relevance of stock market shocks rises significantly. This finding is interesting given the steep decline in the correlation between exchange rates and oil prices that occurred during the period of the financial crisis (see Figure 1), which might indicate that risk shocks are responsible for this decline. We will confirm this hypothesis in the next section when we examine the historical decomposition of the correlation between oil prices and exchange rates.

\footnotetext{
${ }^{21}$ Although Panel A shows the weighted average of the variance decomposition over all regimes, and thus also including the volatile regime, the variance decomposition of oil prices and exchange rates in relation to VIX shocks is similar in Panel A as in the tranquil regime. i.e. $6.8 \%$ and $6.5 \%$.
} 


\subsection{Historical decomposition: explaining the negative correlation between oil and exchange rates}

Finally, turning back to the intriguing negative correlation between oil prices and the US dollar since 2003, our model can account well for the level and dynamics of this correlation. Most importantly, oil shocks, exchange rate shocks and financialisation explain the overall dynamics in the correlation, and the strong increase in the negative correlation since 2007 and during the financial crisis and European sovereign debt crisis is mainly driven by an increased dominance of risk shocks.

In order to understand the correlation between oil prices and exchange rates, we compute the historical decomposition, which gives the contribution of each of the structural shocks in explaining a specific variable at each point in time over our sample period. Using these series, we can generate the implied correlation between exchange rates and oil prices explained by the different shocks in our model. Specifically, we calculate the implied rolling correlation over a 12-month window and compare this with the observed correlation in order to get an estimate of the contribution of the different shocks to the correlation. The results are given in Panel A of Figure $2 .{ }^{22}$ In sum, our model is able to explain both the dynamics and the downward trend of the correlation between oil prices and exchange rates. In particular, the dynamics can mainly be explained by exchange rate and oil shocks, and the downward shift is partly driven by the financialisation process but mainly by an increased importance of risk shocks. We arrive at this conclusion through the following observations.

First, there is a close co-movement between the dynamics in the actual correlation (black line) and the dynamics of the correlation that is only driven by the causal effect, i.e. the correlation between the oil price evolution driven by exchange rates shocks and the exchange rate evolution driven by oil shocks (green dashed line in upper left corner). This is also the case for the implied correlation between oil prices driven by oil shocks only and exchange rates driven by exchange rate shocks only (purple line in upper left corner). This close co-movement in dynamics shows that the fluctuations in the observed correlation between oil prices and exchange rates can mainly be explained by shocks to oil and to the exchange rate. In addition, shocks to open interest in the oil futures market also played some role as the implied correlation based on these shocks also moves closely in line with the observed correlation, in particular towards the end of our sample (blue line in upper right corner).

In order to understand these dynamics better, we can distinguish four possible scenarios that can affect the correlation between exchange rates and oil prices differently. A decline in the correlation can occur when: (i) only oil shocks happen, (ii) only exchange rate shocks occur, and if (iii) the shocks to oil prices and to exchange rates go in opposite directions. ${ }^{23}$ In contrast, the correlation between exchange rates and oil prices can become less negative when the shocks to oil and exchange rates move in the same direction. For example, a negative oil shock which pushes down oil prices and leads to an appreciation of the US dollar could be offset by a negative exchange rate shock in the same period which offsets the rise in the US dollar and increases oil prices again. Therefore, the correlation between exchange rates and oil prices will move according to the combination of shocks

\footnotetext{
${ }^{22}$ As the interest rate shock has no significant overall impact on oil prices and exchange rates, we do not include the implied correlation based on the interest rate shocks in our analysis of the historical decomposition.

${ }^{23}$ For example, a decline in oil prices driven by a negative oil shock is associated with an increase in the US dollar exchange rate. A positive exchange rate shock that occurs in the same period will also drive the US dollar up and oil prices down, contributing to the negative correlation between the two.
} 
in the economy. This is also exactly what we observe in the data. Figure A.2 in the appendix displays the evolution of oil prices and exchange rates over our sample period. The periods in which shocks drive oil prices and exchange rates in opposite directions correspond well with the periods in which also the implied correlation driven by the own oil and exchange rate shocks strengthens, and vice versa.

Second, although the dynamics of the correlation can be well explained by the exchange rate and oil shocks, the explanation for the decline in the observed correlation has to be found elsewhere. Panel A of Figure 2 clearly shows that the shocks explaining the downward shift are the shocks to open interest in the oil futures markets, to stock market returns and to the VIX in particular. First, positive shocks to oil futures markets drove down the implied correlation from a level of around -0.2 to -0.5 over the period 2002:01 - 2008:11 (blue line in upper right corner). The actual rolling correlation declined with about 0.5 over that time period. This result indicates that the increased financialisation of the oil futures market contributed in a non-negligible way to the intensification of the correlation between oil prices and exchange rates, as oil prices for example were increasingly used to hedge against depreciations in the US dollar exchange rate. This implies that oil has increasingly been used as an asset class. Shocks to stock returns contributed 0.25 to the decline in the observed correlation (yellow line in lower left corner). However, the most part of the recent strengthening of the correlation between exchange rates and oil prices is driven by shocks to the VIX as the implied correlation declines from -0.43 to -0.90 over the period 2002:01 - 2008:11 (red line in lower right corner). Interestingly, this implies that the correlation between exchange rates and oil prices became increasingly negative because of an increased importance of risk shocks, which drives both variables in opposite directions.

Panel B in Figure 2 illustrates this by showing a strong co-movement between the implied correlation based on risk shocks, and the rolling standard deviation of the structural VIX shocks that we identify. In the beginning of 2007, there is a clear upward level shift in the standard deviation of the structural VIX shocks, which coincides with a downward shift in the implied correlation. In addition, the two major spikes in the structural shock series, corresponding to the financial crisis and the sovereign debt crisis, are associated with a significant decline in the correlation between exchange rates and oil prices. Hence, we can conclude that exchange rate shocks, oil shocks and oil futures market shocks are responsible for the dynamics in the correlation over time but that the strengthening of the negative co-movement is explained by financialisation and stock return shocks to some extent, and by an increased importance of risk shocks in particular.

\subsection{Time variation in the causality between oil prices, exchange rates and other asset prices}

Figure 1 in the introduction already showed that the correlation between exchange rates and oil prices drastically changed over time, and that it has grown stronger since the early 2000s, at which we also found a structural break in our model. Figure 3 illustrates the changed relationship from a different perspective by displaying the realizations of exchange rates and oil prices in a scatter plot; Panel A shows the scatterplot over the sample 1986-2000 and Panel B the one over the period 2001- 
2012. ${ }^{24}$ It is clear that the link between exchange rates and oil prices has substantially changed since 2001; whereas the correlation does not display any significant relationship in the first sample, the link between exchange rates and oil prices is clearly negative in the second period, which corresponds to the sample used in our model.

To examine the time variation in the link between oil prices and exchange rates, we re-estimate our model over the sample 1986-2000 and compare these with the baseline results. The direct effects between exchange rates and oil prices are shown in Figure 3, and the full set of estimated direct and indirect effects and the variance decomposition can be found in Table A.1 in the appendix.

Remarkably, the response of oil prices to exchange rate shocks, as well as the effect of oil shocks on exchange rates, is much smaller and loses its significance. Indirectly, in contrast to the more recent sample in which higher oil prices lead to a depreciation of the US dollar, oil shocks caused the exchange rate to appreciate. This is in line with previous studies which analyzed the link between the two using data before 2000 (e.g. Amano and van Norden 1998). Interestingly, before 2001, oil in general does not react to the other asset prices included in the model, neither directly nor indirectly. In particular, the magnitude of the VIX and the stock market return shock parameters decline substantially. This is confirmed by the variance decompositions, see Panel B of Table A.1. Almost all of the daily variation of oil prices is explained by own shocks, and the contribution of the VIX and stock market return shocks drops to near zero. ${ }^{25}$

These findings have interesting implications; as oil prices only started to reflect information present in other asset prices from the early 2000s on, the variation in the behavior of oil prices over time could be caused by the increased use of oil as a financial asset since then. Indeed, looking at the effects following the shock to open interest, it is clear that changes in the use of the oil futures market only affected daily oil price movements after 2001, which is exactly the period in which the oil market became increasingly 'financialized'.

\section{Robustness of the results}

In this section, we will test our main findings for their robustness. As a first test, we increase the threshold we use to identify the regimes from 0.8 to 1.0 times the standard deviation. As can be seen from Table A.2 in the appendix, this significantly reshuffles the number of observations per regime. Overall, the results remain robust to this re-specification of regimes. In particular, we obtain coefficient estimates that are close to our baseline specification in magnitude and significance for the bidirectional causality between oil prices and the exchange rate and for the overall effect of

\footnotetext{
${ }^{24}$ In order to gain additional years of data history we use the VXO instead of the VIX. Furthermore, for the years 1986-88 we use New York noon exchange rates.

${ }^{25}$ The historical decompositions for the early sample confirm that the correlation between oil prices and exchange rates is mainly driven by own shocks. We decided not to show the implied correlations as none of the shocks in this sample has a significant effect on both oil prices and exchange rates, and the implied correlations are subsequently not statistically different from zero.
} 
demand shocks to oil prices and for risk shocks to the oil price and the exchange rate. Detailed results can be found in Table A.3 in the appendix.

Secondly, we estimate our model excluding the second half-year of 2008. During this period the US dollar experienced a strong appreciation induced by a flight-to-safety run following the collapse of Lehman brothers. During the same period the price of oil dropped by a stunning $80 \%$ (see Figure A. 2 . in the appendix). By excluding this period, we examine whether our results are driven by the extraordinary events of that time. Table A.4 in the appendix shows that the main conclusions of this paper hold; oil prices immediately reflect information contained in the other asset prices, there is a direct causal link between oil prices and exchange rates, and VIX and stock market shocks remain relevant for explaining variation in both the oil price and the exchange rate.

Next, since our regime definitions depend on the volatility of VAR residuals and since the decomposition of the residual covariance matrices is at the heart of our estimator, we increase the lag length of our model from 2 to 5 . Again, the results do not significantly change. ${ }^{26}$

Finally, since our estimator is based on a highly parameterized optimization, we vary starting values to adduce evidence that our estimates correspond to the global maximum of the objective function. The default starting values are 0.1 for all parameters. We reset this value to 0.3 . Also, we apply starting values that are incremented over the coefficients. Under both variations, coefficient estimates are identical up to four significant digits.

\section{Conclusion}

This paper analyzes the causality between oil and asset prices - and in particular between oil prices and exchange rates - using an identification methodology that exploits the heteroskedasticity of the underlying time-series data and that is well suited to overcome conventional problems in simultaneous equation models (Rigobon 2003). By using this approach and high-frequency daily data, we explicitly take a financial market perspective for analyzing the interactions between oil prices, exchange rates and asset prices.

Several important results emerge from our analysis. First, we find that oil prices in general immediately react to changes in other financial assets. The causality between oil prices and exchange rates runs negative in both directions; a $10 \%$ increase in the price of oil leads to a depreciation of the US dollar effective exchange rate by $0.28 \%$ on impact, whilst a weakening of the US dollar with $1 \%$ causes oil prices to rise by $0.73 \%$. Even though we find statistically significant estimates for the link between exchange rates and oil prices, the variance decomposition shows that the economic relevance of exchange rate movements in explaining overall fluctuations in oil prices is limited, which is also true for the reverse effect.

\footnotetext{
${ }^{26}$ The results for changes in the lag length and variation in the starting values are available from the authors upon request.
} 
Second, equity market shocks and risk shocks have been important drivers of oil prices and of the US dollar exchange rate since 2001 . A positive US equity market shock raises oil prices - similar to what a positive shock to economic activity would do - whereas a rise in financial market risk lowers oil prices while inducing a US dollar appreciation - which may be indicative of a flight-to-safety phenomenon. As to the economic significance, shocks to US equity markets and risk explain overall about $10 \%$ of the daily variations in oil prices and in exchange rates, which doubles in volatile crisis periods.

Third, the behavior of oil as a financial asset - in that it immediately reflects information of other asset prices - was largely absent before the early 2000s. This change might be caused by the increased use of oil as a financial asset since then. In line with this, we find that shocks to open interest in the oil futures market only affected oil prices after 2001, which is exactly the period in which the oil market became increasingly 'financialized'.

Finally, we show that our model can account well for the intriguing negative and rising correlation between oil prices and exchange rates since the early 2000s. The estimates indicate that it has been in particular the financialisation of oil markets in the mid-2000s and subsequently the sharp rise in risk and uncertainty since the 2007 global financial crisis that explain the increase in the negative correlation between oil prices and exchange rates. 


\section{References}

Amano, R.A. and N.S. van Norden (1998): Oil Prices and the Rise and Fall of the US Real Exchange Rate. Journal of International Money and Finance, 17, 299-316.

Andersen, T.G., Bollerslev, T., Diebold, F.X. and C. Vega (2003): Micro Effects of Macro Announcements: Real-time Price Discovery in Foreign Exchange. American Economic Review, 93 (1), 38-62.

Andersen, T., Bollerslev, T., Diebold, F. and C. Vega (2007): Real-Time Price Discovery in Stock, Bond and Foreign Exchange Markets. Journal of International Economics, 73, 251-277.

Andrews, D.W. (1993): Tests for Parameter Instability and Structural Change. Econometrica, 63 (4), 821-856.

Backus, D.K. and M.J. Crucini (2000): Oil Prices and the Terms of Trade. Journal of International Economics, 50, 185-213.

Bekaert, G., Hoerowa, M. and M. Lo Duca (2012): Risk, Uncertainty and Monetary Policy. Working Paper, National Bank of Belgium.

Benassy-Quere, A., Mignon, V. and A. Penot (2007): China and the Relationship between the Oil Price and the Dollar. Energy Policy, 35(11), 5795-5805.

Bernanke, B. S. and K. N. Kuttner (2005): What Explains the Stock Market's Reaction to Federal Reserve Policy? Journal of Finance, 60, 1221-1257.

Bodenstein, M., Erceg, C.J. and L. Guerrieri (2011): Oil Shocks and External Adjustment. Journal of International Economics, 83, 168-184.

Bouakez, H. and M. Normandin (2010): Fluctuations in the foreign exchange market: How important are monetary policy shocks? Journal of International Economics, 81, 139-153.

Breitenfellner, A. and J.C. Cuaresma (2008): Crude Oil Prices and the USD/EUR Exchange Rate. Monetary Policy and the Economy, Q4/08, 102-121.

Buetzer, S., Habib, M.M. and L. Stracca (2012): Global Exchange Rate Configurations: Do Oil Shocks Matter? Working Paper, European Central Bank.

Chen, H. and S. Chen (2007): Oil Prices and Real Exchange Rates. Energy Economics, 29 (3), 390-404.

Chen, Y., Rogoff, K.S. and B. Rossi (2010): Can Exchange Rates Forecast Commodity Prices? Quarterly Journal of Economics, 125 (3), 1145-1194.

Chaudhuri, K. and B.C. Daniel (1998): Long-run Equilibrium Real Exchange Rates and Oil Prices. Economics Letters, 58, 231-238. 
Chinn, M. and K. J. Forbes (2004): A Decomposition of Global Linkages in Financial Markets Over Time. Review of Economics and Statistics, 86, 705-722.

Coudert, V., Mignon, V. and A. Penot (2008): Oil Price and the Dollar. Energy Studies Review, 15(2), Article 3.

De Schryder, S. and G. Peersman (2012): The US Dollar Exchange Rate and the Demand for Oil. CESifo Working Paper no. 4126.

Diebold, F. and K. Yilmaz (2009): Measuring Financial Asset Return and Volatility Spillovers, with Application to Global Equity Markets. Economic Journal, 119, 158-171.

Dungey, M. and V. L. Martin (2007): Unravelling Financial Market Linkages During Crises. Journal of Applied Econometrics, 22 (1), 89-119.

Ehrmann, M. and M. Fratzscher (2005): Equal size, equal role? Interest rate interdependence between the euro area and the United States. Economic Journal, 115, 930-950.

Ehrmann, M., Fratzscher, M. and R. Rigobon (2011): Stocks, Bonds, Money Markets and Exchange Rates: Measuring International Financial Transmission. Journal of Applied Econometrics, 26, 948974.

Engel, C., Mark, N.C. and K.D. West (2007): Exchange Rate Models Are Not as Bad as You Think. NBER Macroeconomics Annual, Vol. 22 (2007), pp. 381-441.

Fan, Y., Tsai, H., Wei, Y. and Y. Zhang (2008): Spillover Effect of US Dollar Exchange Rate on Oil Prices. Journal of Policy Modeling, 30, 973-991.

Faust, J., Rogers, J.H., Wang, S.B. and J.H. Wright (2007): The High-frequency Response of Exchange Rates and Interest Rates to Macroeconomic Announcements. Journal of Monetary Economics, 54, 1051-1068.

Frankel, J.A. (2008): The Effect of Monetary Policy on Real Commodity Prices. In: Campbell, J.Y. (Ed.): Asset Prices and Monetary Policy. Chicago: University of Chicago Press.

Fratzscher, M. (2009): What Explains Global Exchange Rate Movements during the Financial Crisis? Journal of International Money and Finance, 28, 1390-1407.

Ferraro, D., Rogoff, K.S. and B. Rossi (2012): Can Oil Prices Forecast Exchange Rates? National Bureau of Economic Research, Working Paper No.17998.

Golub, S.S. (1983): Oil Prices and Exchange Rates. The Economic Journal, 93, 576-593.

Gravelle, T., Kichian, M. and J. Morley (2006). Journal of International Economics, 68, 409-423.

Hamilton, J.D. (2009): Causes and Consequences of the Oil Shock of 2007-08. Brookings Papers in Economic Activity, 40 (1), 215-283. 
Herwartz, H. and H. Lütkepohl (2011): Structural Vector Autogregressions with Markov Switching: Combining Conventional with Statistical Identification of Shocks. European University Institute, Working Paper No.2011/11.

Huang, A.Y. and Y. Tseng (2010): Is Crude Oil Price Affected by the US Dollar Exchange Rate? International Research Journal of Finance and Economics, 58, 109-120.

Kilian, L. (2009): Not All Oil Price Shocks Are Alike: Disentangling Demand and Supply Shocks in the Crude Oil Market. American Economic Review, 99 (3), 1053-1069.

Kilian, L. (2012): Structural Vector Autoregressions. Forthcoming in: N. Hashimzade and M. Thornton (eds.): Handbook of Research Methods and Applications in Empirical Macroeconomics. Camberley, UK, Edward Elgar.

Kilian, L. and C. Park (2009): The Impact of Oil Price Shocks on the U.S. Stock Market. International Economic Review, 50 (4), 1267-1287.

Kilian, L. and C. Vega (2011): Do Energy Prices Respond to U.S. Macroeconomic News? A Test of the Hypothesis of Predetermined Energy Prices. The Review of Economics and Statistics, 93 (2), 660-671.

Kilian, L., Rebucci, A. and N. Spatafora (2009): Oil Shocks and External Balances. Journal of International Economics, 77, 181-194.

Krugman, P.R. (1983): Oil Shocks and Exchange Rate Dynamics. In: Frenkel, J.A. (Ed.): Exchange Rates and International Macroeconomics. University of Chicago Press.

Lanne, M. and H. Lütkepohl (2008): Identifying Monetary Policy Shocks via Changes in Volatility. Journal of Money, Credit and Banking, 40 (6), 1131-1149.

Lombardi, M.J. and I. Van Robays (2011): Do Financial Investors Destabilize the Oil Price? European Central Bank, Working Paper No.1346.

Lütkepohl, H. and A. Netsunajev (2012): Disentangling Demand and Supply Shocks in the Crude Oil Market. DIW Discussion Papers No.1195.

Peersman, G. and I. Van Robays (2009): Oil and the Euro Area. Economic Policy, 24, 603-651.

Razgallah, B. and K. Smimou (2011): Oil Prices and the Greenback: It Takes Two to Tango. Applied Financial Economics, 21, 519-528.

Rigobon, R. (2003): Identification through Heteroskedasticity. The Review of Economics and Statistics, 85 (4), 777-792.

Rigobon, R. and B. Sack (2003): Measuring the Reaction of Monetary Policy to the Stock Market. Quarterly Journal of Economics, 118, 639-669.

Rigobon, R. and B. Sack (2004): The Impact of Monetary Policy on Asset Prices. Journal of Monetary Economics, 51, 1553-1575. 
Scholl, A. and H. Uhlig (2008): New Evidence on the Puzzles: Results from Agnostic Identification on Monetary Policy and Exchange Rates. Journal of International Economics, 76, 1-13.

Sentana, E. and G. Fiorentini (2001): Identification, Estimation and Testing of Conditionally Heteroskedastic Factor Model. Journal of Econometrics, 102, 143-164.

Sockin, M. and W. Xiong (2012): Feedback Effects of Commodity Futures Prices. Working Paper, Princeton University.

Van Robays, I. (2012): Macroeconomic Uncertainty and the Impact of Oil Shocks. European Central Bank, Working Paper No.1479.

Weber, E. (2008): Macro Wine in Financial Skins: The Oil-FX Interdependence. Freie Universität Berlin, Working Paper No.SFB 649 DP 2008-048.

Wirjanto, T.S. and A. Yousefi (2003): Exchange Rate of the US Dollar and the J-curve: The Case of Oil Exporting Countries. Energy Economics, 25, 741-765.

Wirjanto, T.S. and A. Yousefi (2005): A Stylized Exchange Rate Pass-through Model of Crude Oil Price Formation. OPEC Energy Review, 29 (3), 177-197. 
Figure 1. Rolling correlation between exchange rates and oil prices over time

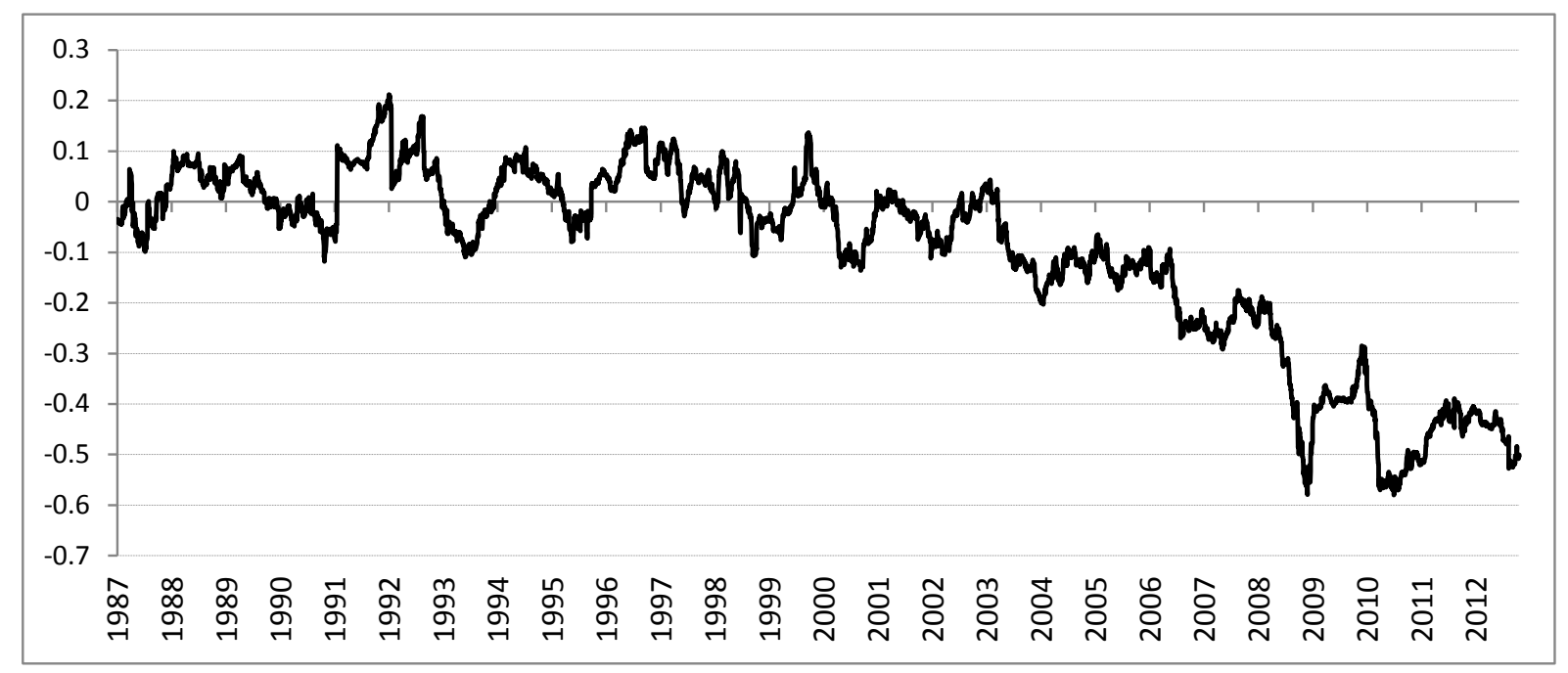

Notes: 12-month rolling average correlation between the log-difference of the effective US dollar exchange rate and WTI crude oil prices using daily data from 1 January 1986 to 19 October 2012. 
Figure 2. Explaining the evolution of the correlation between oil prices and exchange rates

PANEL A: Actual and implied correlation between oil and exchange rates driven by different types of shocks
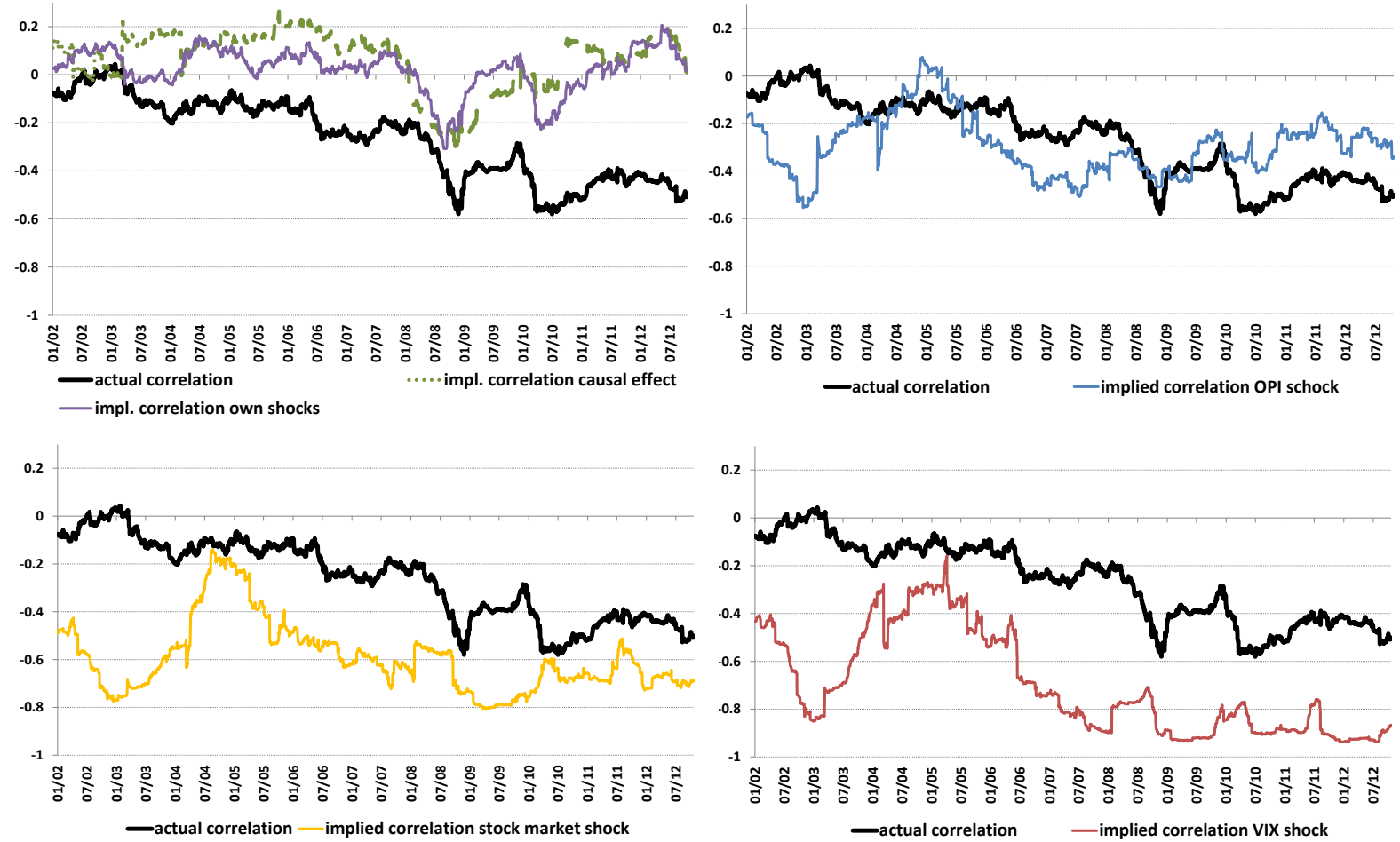

PANEL B: Rolling correlation explained by VIX shock and rolling standard deviation of structural VIX shocks

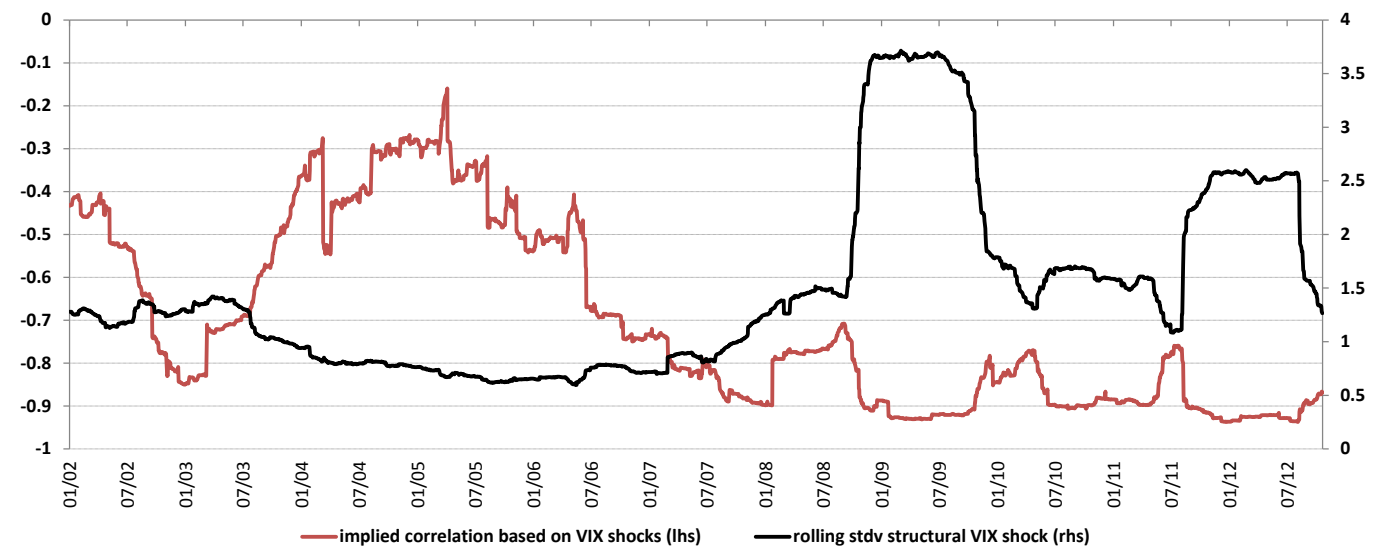

Notes: Panel A shows the comparison between the actual rolling correlation between exchange rates and oil prices and the implied correlations which are calculated as the correlation that is driven by a particular shock using the estimated historical contributions. Panel B shows the comparison of the implied correlation between exchange rates and oil prices based on the VIX shocks and the rolling standard deviation of the identified structural VIX shock. The rolling window for both the correlation and the standard deviation is 12 months. 
Figure 3. Time variation in the causality between exchange rates and oil prices

Panel A: 1986-2000

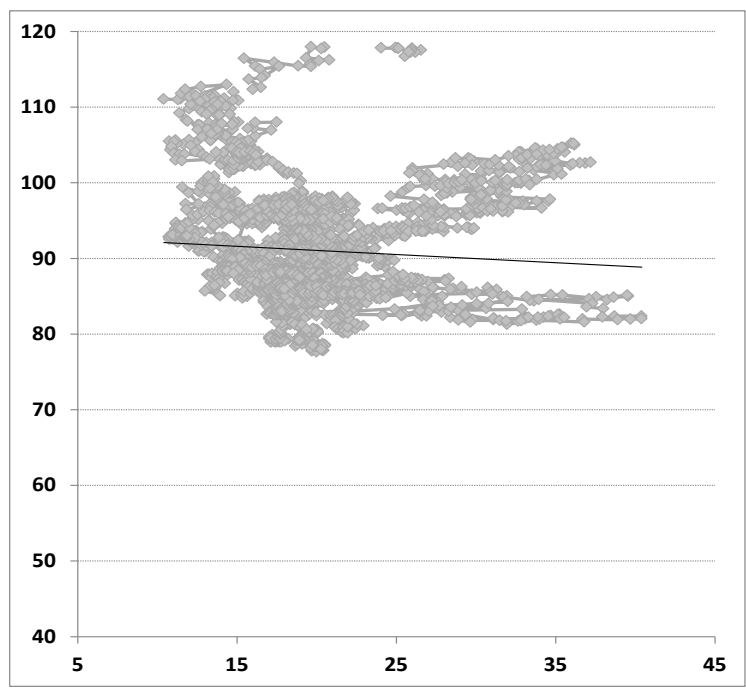

\begin{tabular}{l||c|c} 
& Oil price & Exchange rate \\
\hline Oil price & 1.000 & -0.226 \\
\hline Exchange rate & 0.008 & 1.000
\end{tabular}

Panel B: 2001-2012

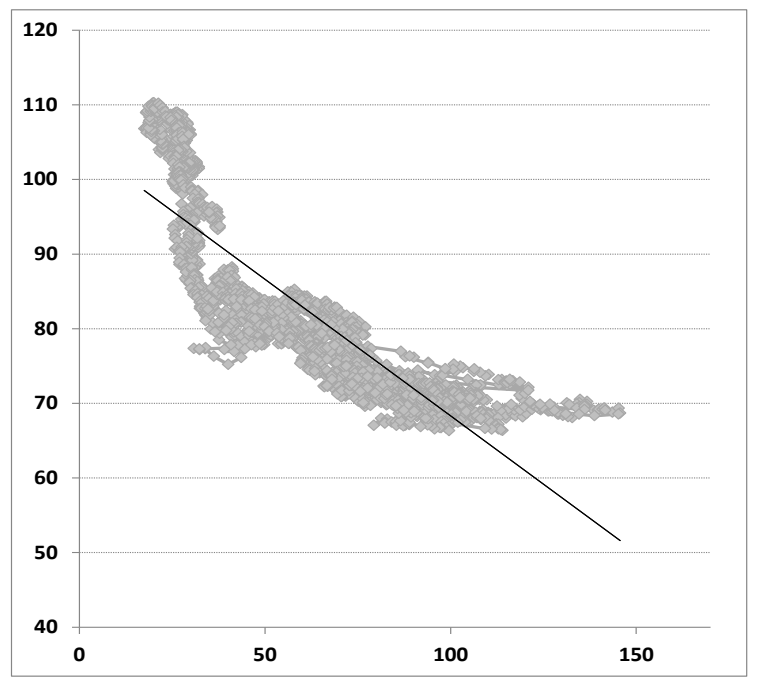

\begin{tabular}{l|c|c} 
& Oil price & Exchange rate \\
\hline Oil price & 1.000 & $-0.729^{* * *}$ \\
\hline Exchange rate & $-0.028^{* * *}$ & 1.000
\end{tabular}

Notes: The charts are the scatter plots of the realizations of exchange rates ( $x$-axis) and oil prices ( $y$-axis) over the periods $02 / 01 / 1986$ $29 / 12 / 2000$ and $01 / 01 / 2001-19 / 10 / 2012$, the numbers in the tables correspond to the estimated direct effects captured in the A matrix over the different samples. ${ }^{*}, *$ and $* * *$ denote significance at the $1 \%, 5 \%$ and $10 \%$ levels. 
Table 1. Variance-covariance of the reduced form shocks in the different regimes

\begin{tabular}{|c|c|c|c|c|c|}
\hline & $\begin{array}{l}\text { Tranquil period: All } \\
\text { variables tranquil }\end{array}$ & $\begin{array}{l}\text { Regime 1: Oil prices } \\
\text { volatile }\end{array}$ & $\begin{array}{l}\text { Regime } 2 \text { : Exchange } \\
\text { rates volatile }\end{array}$ & $\begin{array}{l}\text { Regime 3: Oil prices } \\
+ \text { exchange rates }\end{array}$ & $\begin{array}{l}\text { Regime 4: All } \\
\text { variables volatile }\end{array}$ \\
\hline Oil prices & 4.349 & 7.267 & 2.128 & 7.856 & 16.275 \\
\hline Exchange rates & 0.138 & 0.120 & 0.252 & 0.270 & 0.547 \\
\hline Stock prices & 0.793 & 0.635 & 0.645 & 0.752 & 5.046 \\
\hline Interest rates & 0.001 & 0.000 & 0.000 & 0.000 & 0.027 \\
\hline VIX & 1.658 & 0.763 & 0.902 & 0.801 & 12.419 \\
\hline Open interest & 0.125 & 0.263 & 0.211 & 0.280 & 0.250 \\
\hline No. observations & $38 \%$ & $13 \%$ & $20 \%$ & $16 \%$ & $14 \%$ \\
\hline $\begin{array}{l}\text { Covariance oil price } \\
\text { and exchange rates }\end{array}$ & -0.160 & -0.223 & -0.190 & -0.431 & -1.328 \\
\hline
\end{tabular}

Notes: The reduced form is estimated using data from 5 January 2002 - 19 October 2012, the number of observations is expressed as a percentage of the total observations in the 5 regimes combined. 
Table 2. Direct and overall effects: $A$ and $A^{-1}$ matrix

STRUCTURAL SHOCKS

\begin{tabular}{|c|c|c|c|c|c|c|}
\hline DIRECT EFFECTS & Oil price & Exchange rate & Stock returns & Interest rate & VIX & OPI \\
\hline Oil price & 1.000 & $-0.729 * * *$ & 0.200 & $6.063 * *$ & $-0.332^{* *}$ & $0.609 * *$ \\
\hline Exchange rate & $-0.028 * * *$ & 1.000 & -0.113 & 0.343 & -0.010 & -0.036 \\
\hline Stock returns & -0.025 & -0.035 & 1.000 & $-5.153^{* *}$ & $-0.440 * * *$ & -0.014 \\
\hline Interest rates & $-0.006^{*}$ & -0.015 & $0.070 * *$ & 1.000 & 0.040 & -0.010 \\
\hline VIX & $0.031 * *$ & 0.111 & $-0.420 * * *$ & -2.294 & 1.000 & 0.005 \\
\hline Open interest & -0.007 & 0.034 & 0.020 & -0.246 & 0.001 & 1.000 \\
\hline OVERALL EFFECTS & Oil price & Exchange rate & Stock returns & Interest rate & VIX & OPI \\
\hline Oil price & $0.966 * * *$ & $-0.813^{* *}$ & $0.724 * *$ & $2.923^{*}$ & $-0.530 * * *$ & $0.578^{*}$ \\
\hline Exchange rate & $-0.025 * * *$ & $1.022^{* * *}$ & $-0.120 * *$ & 0.608 & $0.096 * * *$ & -0.056 \\
\hline Stock returns & -0.019 & -0.025 & $0.974 * * *$ & -3.824 & $-0.577 * * *$ & 0.009 \\
\hline Interest rates & $-0.005^{*}$ & -0.008 & $0.045^{*}$ & $0.713^{* * *}$ & 0.010 & -0.010 \\
\hline VIX & 0.046 & 0.117 & $-0.504^{*}$ & 0.127 & $1.213^{* * *}$ & 0.036 \\
\hline Open interest & -0.007 & 0.042 & -0.000 & -0.253 & -0.009 & $0.997 * * *$ \\
\hline
\end{tabular}

Notes: Estimated effects following 1\% shocks, based on the estimated structural VAR model over the period 5 January 2001 - 19 October 2012 , including two lags of the endogenous variables and with all variables expressed in first differences. $* * *, * *$ and $*$ denote significance at the $1 \%$, $5 \%$ and $10 \%$ levels. OPI stands for open interest in the NYMEX oil futures market. 
Table 3. Relevance of macroeconomic news

\begin{tabular}{|c|c|c|c|c|c|c|}
\hline & Oil prices & $\begin{array}{l}\text { Exchange } \\
\text { rates }\end{array}$ & Stock market & Interest rates & VIX & $\begin{array}{l}\text { Open } \\
\text { interest }\end{array}$ \\
\hline Fed surprise & -3.129 & 2.714 & $-7.726 * * *$ & 0.057 & $8.322 * *$ & -0.746 \\
\hline Real GDP, Advance & -0.866 & 0.256 & 0.174 & 0.005 & 0.022 & -0.385 \\
\hline $\mathrm{CPI}$ & -0.276 & 0.137 & 0.080 & 0.006 & 0.026 & -0.061 \\
\hline Industrial production & -0.191 & 0.028 & 0.090 & -0.016 & 0.154 & -0.001 \\
\hline Total Nonfarm payroll & $0.754^{*}$ & $0.372^{* * *}$ & 0.259 & $0.025 * * *$ & 0.226 & -0.003 \\
\hline Retail Sales & 0.193 & 0.046 & $0.244^{*}$ & 0.005 & $-0.571^{* *}$ & 0.143 \\
\hline Unemployment Rate & 1.780 & $-1.326 * * *$ & -0.812 & -0.047 & 0.970 & 0.459 \\
\hline Consumer Confidence & -0.058 & 0.231 & -0.803 & $0.031^{* *}$ & 0.864 & -0.044 \\
\hline Housing Starts & -0.441 & 0.123 & 0.510 & -0.018 & -0.528 & 0.195 \\
\hline Purchasing Managers Index & 0.739 & 0.093 & 0.191 & 0.005 & 0.035 & 0.127 \\
\hline PPI & -0.049 & -0.013 & -0.052 & 0.000 & 0.114 & -0.042 \\
\hline Trade Balance & 0.104 & 0.288 & 0.856 & -0.013 & $-1.355^{*}$ & -0.199 \\
\hline Average Weekly Hours & -0.113 & -0.127 & 0.020 & -0.007 & 0.416 & $-0.505^{* *}$ \\
\hline F-test joint sign. (p-value) & $0.74(0.73)$ & $2.69 * * *(0.00)$ & $1.36(0.17)$ & $1.52 *(0.10)$ & $1.29(0.21)$ & $1.08(0.37)$ \\
\hline
\end{tabular}

Notes: The results are based on the estimated structural VAR model over the period 1 January 2001 - 19 October 2012 with the news components included as exogenous variables. The news variables correspond to the unexpected components which are measured as the difference between the expectations and the actual announcements. The p-values are based on heteroskedasticity robust standard errors, and $* * *, * *$ and $*$ denote significance at the $1 \%, 5 \%$ and $10 \%$ levels. 
Table 4. Variance decompositions over different regimes

\section{CONTRIBUTION OF SHOCKS}

\begin{tabular}{|c|c|c|c|c|c|c|}
\hline PANEL A: weight. average & Oil price & Exchange rate & Stock returns & Interest rate & VIX & OPI \\
\hline Oil price & 83.9 & 2.7 & 5.2 & 0.7 & 6.3 & 1.3 \\
\hline Exchange rate & 1.6 & 88.5 & 3.5 & 0.8 & 5.3 & 0.3 \\
\hline Stock returns & 0.2 & 0.0 & 55.2 & 6.1 & 38.4 & 0.0 \\
\hline Interest rates & 3.9 & 0.5 & 33.3 & 58.1 & 3.5 & 0.7 \\
\hline VIX & 0.9 & 0.2 & 8.5 & 0.0 & 90.4 & 0.0 \\
\hline OPI & 0.1 & 0.2 & 0.0 & 0.2 & 0.1 & 99.4 \\
\hline PANEL B: all volatile & & & & & & \\
\hline Oil price & 74.8 & 1.7 & 7.4 & 1.8 & 13.8 & 0.5 \\
\hline Exchange rate & 1.5 & 76.9 & 5.9 & 2.3 & 13.3 & 0.1 \\
\hline Stock returns & 0.1 & 0.0 & 40.7 & 9.4 & 49.8 & 0.0 \\
\hline Interest rates & 1.3 & 0.1 & 20.1 & 74.7 & 3.7 & 0.1 \\
\hline VIX & 0.2 & 0.0 & 4.7 & 0.0 & 95.0 & 0.0 \\
\hline OPI & 0.3 & 0.3 & 0.0 & 0.9 & 0.3 & 98.3 \\
\hline
\end{tabular}

Notes: The results are based on the forecast error decomposition over the horizon of one day and units are in percentages. Panel A gives the weighted average of the variance decompositions across the different regimes with the numbers of observations in each regime as a weight. Panel B shows the variance decomposition for the regime in which all endogenous variables have increased variance. OPI stands for open interest in the oil futures market. 


\section{Appendix: Figures and Tables}

Figure A.1. Interpretation of the structural shocks series
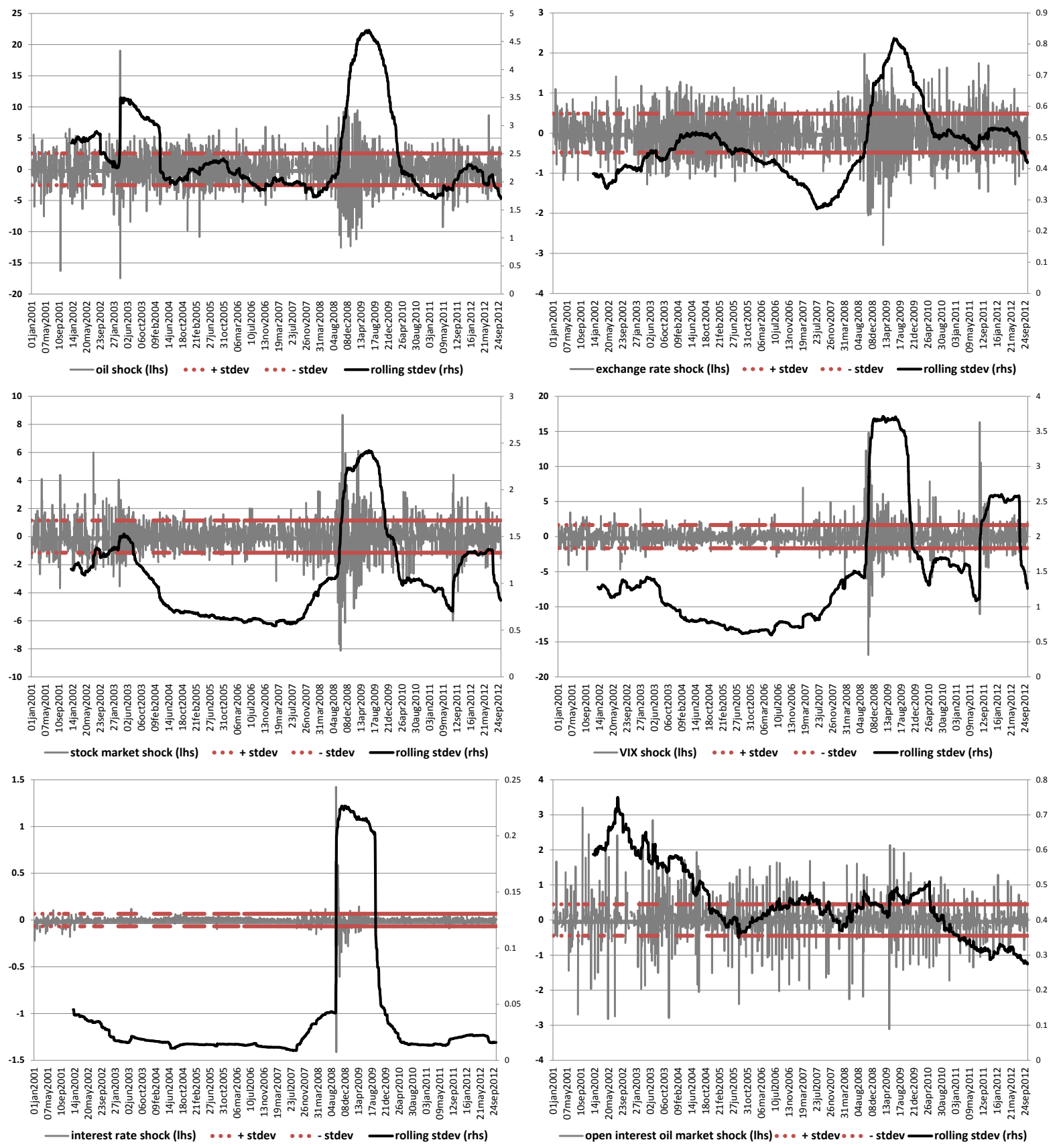

Notes: the grey bares are the daily estimated structural shock series together with the average standard deviation bounds indicated by the dotted red lines, and the black full lines show the 12-month rolling standard deviation of the structural shock series. The structural shock series are estimated using identification though heteroskedasticity applied to the 6-variable VAR model shown in equation (1) over the sample 1 January 2001 - 19 October 2012. 
Figure A.2. Evolution of WTI crude oil price and effective US dollar exchange rate

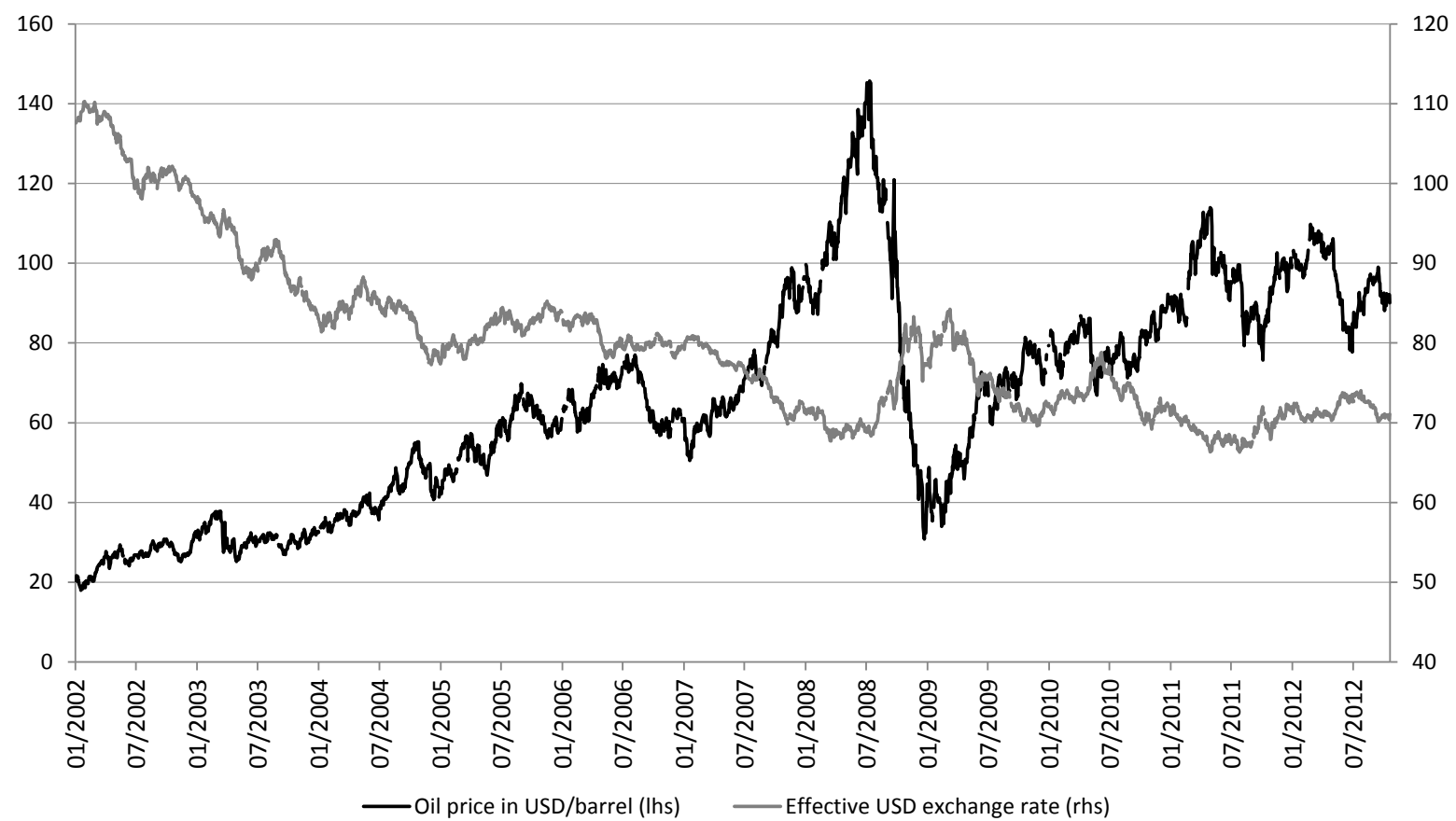

Notes: daily data, the oil price is the nominal WTI crude oil price in USD per barrel (left hand scale) and the exchange rate is effective US dollar exchange rate, 1998=100 (right hand scale). 
Table A.1. Direct and overall effects and variance decomposition over period 1986-2000

Panel A: direct and overall effects over sample period $1986-2000$

STRUCTURAL SHOCKS

\begin{tabular}{|c|c|c|c|c|c|c|}
\hline DIRECT EFFECTS & Oil price & Exchange rate & Stock returns & Interest rate & VIX & OPI \\
\hline Oil price & 1.000 & -0.226 & -0.080 & -2.517 & -0.021 & -0.071 \\
\hline Exchange rate & 0.008 & 1.000 & -0.026 & 0.571 & -0.003 & -0.078 \\
\hline Stock returns & 0.002 & 0.226 & 1.000 & $-15.919 * * *$ & $-0.224 * * *$ & 0.009 \\
\hline Interest rates & $0.004 * *$ & 0.027 & 0.015 & 1.000 & -0.001 & 0.004 \\
\hline VIX & -0.014 & 0.183 & $-1.014 * * *$ & $14.441 * *$ & 1.000 & 0.151 \\
\hline Open interest & 0.015 & 0.309 & $0.181^{*}$ & -1.220 & $0.061 * *$ & 1.000 \\
\hline OVERALL EFFECTS & Oil price & Exchange rate & Stock returns & Interest rate & VIX & OPI \\
\hline Oil price & $0.992 * * *$ & -0.292 & -0.096 & -1.067 & -0.000 & -0.052 \\
\hline Exchange rate & $0.011^{*}$ & $0.994 * * *$ & -0.023 & 0.934 & -0.004 & -0.075 \\
\hline Stock returns & $-0.068 * *$ & -0.290 & $0.942 * * *$ & $-17.682 * * *$ & $-0.186 * * *$ & -0.001 \\
\hline Interest rates & $0.003 * * *$ & 0.022 & 0.014 & $0.718^{* * *}$ & $-0.004^{*}$ & 0.001 \\
\hline VIX & $0.100 * *$ & 0.754 & $-0.768 * * *$ & $28.791 * * *$ & $1.123^{* * *}$ & -0.136 \\
\hline Open interest & 0.009 & 0.269 & 0.098 & -2.053 & $0.038 * * *$ & $0.966 * * *$ \\
\hline
\end{tabular}

Panel B: historical variance decomposition over sample period 1986 - 2000

CONTRIBUTION OF SHOCKS

\begin{tabular}{|c|c|c|c|c|c|c|}
\hline PANEL A: weight. average & Oil price & Exchange rate & Stock returns & Interest rate & VIX & OPI \\
\hline Oil price & 99.3 & 0.4 & 0.2 & 0.1 & 0.0 & 0.0 \\
\hline Exchange rate & 0.6 & 95.9 & 0.3 & 1.4 & 0.1 & 1.8 \\
\hline Stock returns & 1.8 & 0.8 & 45.6 & 43.6 & 8.3 & 0.0 \\
\hline Interest rates & 4.0 & 5.0 & 10.9 & 75.7 & 4.3 & 0.1 \\
\hline VIX & 1.2 & 1.8 & 8.7 & 31.8 & 56.3 & 0.2 \\
\hline OPI & 0.1 & 2.8 & 1.9 & 2.4 & 1.7 & 91.1 \\
\hline PANEL B: all volatile & & & & & & \\
\hline Oil price & 99.7 & 0.1 & 0.1 & 0.0 & 0.0 & 0.0 \\
\hline Exchange rate & 0.9 & 95.7 & 0.4 & 1.8 & 0.1 & 1.2 \\
\hline Stock returns & 2.1 & 0.5 & 47.9 & 40.4 & 9.2 & 0.0 \\
\hline Interest rates & 4.9 & 3.3 & 12.1 & 74.6 & 5.1 & 0.0 \\
\hline VIX & 0.9 & 0.7 & 6.6 & 22.3 & 69.3 & 0.1 \\
\hline OPI & 0.2 & 3.1 & 3.7 & 3.9 & 2.7 & 86.4 \\
\hline
\end{tabular}

Notes: based on the estimated structural VAR model over the period 02/01/1986 - 29/12/2000. ***, ${ }^{* *}$ and * denote significance at the $1 \%, 5 \%$ and $10 \%$ levels. The results are based on the forecast error decomposition over the horizon of one day and units are in percentages. Panel A gives the weighted average of the variance decompositions across the different regimes with the numbers of observations in each regime as a weight. Panel B shows the variance decomposition for the regime in which all endogenous variables have increased variance. OPI stands for open interest in the oil futures market. 
Table A.2. Number of observations per regime for different volatility thresholds.

\begin{tabular}{l|r|r} 
& \multicolumn{2}{|c}{ Threshold } \\
\hline Regime & \multicolumn{1}{|c|}{$\mathbf{0 . 8}$} & \multicolumn{1}{c}{$\mathbf{1}$} \\
\hline \hline \multicolumn{1}{l||}{ Tranquil } & 817 & 1226 \\
\hline Oil price & 269 & 210 \\
\hline Exchange rate & 421 & 402 \\
\hline Oil and exch. rate & 337 & 161 \\
\hline All variables & 293 & 152 \\
\hline
\end{tabular}

Notes: Table cells indicate the number of observations per heteroskedastic regime chosen by a certain volatility threshold. An observation of a variable is judged to be of elevated volatility if the 5-day rolling standard deviation of its associated reduced-form VAR residual is above a threshold, which is expressed as a factor multiplying the standard deviation of the residual series over the entire time horizon of the VAR. The table considers factors of 0.8 and 1.

Table A.3. Direct and overall effects for a higher threshold for regime determination.

STRUCTURAL SHOCKS

\begin{tabular}{|c|c|c|c|c|c|c|}
\hline DIRECT & Oil price & Exchange rate & Stock returns & Interest rate & VIX & \\
\hline Oil price & 1 & $0.716 * *$ & -0.506 & $-5.848 * *$ & 0.217 & -0.635 \\
\hline Exchange rate & $0.031 * * *$ & 1 & 0.006 & 0.318 & -0.05 & -0.094 \\
\hline Stock returns & 0.041 & 0.246 & 1 & $4.266^{* *}$ & $0.438 * * *$ & 0.182 \\
\hline Interest rates & $0.006 *$ & 0.008 & $-0.077^{* *}$ & 1 & -0.034 & 0.061 \\
\hline VIX & -0.025 & -0.25 & $0.488^{* * *}$ & -0.557 & 1 & 0.129 \\
\hline Open interest & 0.011 & -0.052 & -0.1 & 0.652 & -0.04 & 1 \\
\hline
\end{tabular}

STRUCTURAL SHOCKS

\begin{tabular}{|c|c|c|c|c|c|c|}
\hline OVERALL & Oil price & Exchange rate & Stock returns & Interest rate & VIX & Open interest \\
\hline Oil price & $0.968 * * *$ & $-1.072^{*}$ & 0.939* & 1.439 & $-0.613 * * *$ & 0.335 \\
\hline Exchange rate & $-0.028 * * *$ & $1.066 * * *$ & -0.07 & -0.222 & $0.086 * * *$ & 0.098 \\
\hline Stock returns & -0.020 & -0.317 & $0.942 * * *$ & -4.438 & $-0.571 * * *$ & 0.13 \\
\hline Interest rates & $-0.005^{* *}$ & -0.018 & 0.051 & $0.799 * * *$ & 0.002 & -0.063 \\
\hline VIX & 0.025 & 0.377 & $-0.429 * * *$ & 2.704 & $1.286 * * *$ & -0.202 \\
\hline Open interest & -0.010 & 0.063 & 0.029 & -0.884 & 0.004 & $1.048 * * *$ \\
\hline
\end{tabular}

Notes: Estimated effects following 1\% shocks, based on the estimated structural VAR model over the period 1 January $2001-19$ October 2012 employing a threshold of 1.0 times the standard deviation as a definition of high volatility. ${ }^{* * *},{ }^{* *}$ and ${ }^{*}$ denote significance at the $1 \%, 5 \%$ and $10 \%$ levels. 
Table A.4. Direct and overall effects based on a sample excluding the post-Lehman half-year.

\section{STRUCTURAL SHOCKS}

\begin{tabular}{|c|c|c|c|c|c|c|}
\hline DIRECT & Oil price & Exchange rate & Stock returns & Interest rate & VIX & \\
\hline Oil price & 1 & $0.791 * *$ & -0.612 & 21.532* & 0.075 & $-0.725 *$ \\
\hline Exchange rate & $0.041 * *$ & 1 & $0.139 *$ & -9.376 & -0.017 & -0.045 \\
\hline Stock returns & 0.022 & 0.152 & 1 & 14.303 & $0.487 * * *$ & 0.001 \\
\hline Interest rates & -0.002 & 0.016 & -0.011 & 1 & -0.006 & 0 \\
\hline VIX & -0.013 & -0.082 & $0.391 * * *$ & -4.08 & 1 & -0.003 \\
\hline Open interest & 0.012 & 0.054 & -0.002 & 1.136 & 0.014 & 1 \\
\hline
\end{tabular}

STRUCTURAL SHOCKS

\begin{tabular}{|c|c|c|c|c|c|c|}
\hline OVERALL & Oil price & Exchange rate & Stock returns & Interest rate & VIX & Open interest \\
\hline Oil price & $0.968 * * *$ & -1.072* & 0.939* & 1.439 & $-0.613 * * *$ & 0.335 \\
\hline Exchange rate & $-0.028 * * *$ & $1.066 * * *$ & -0.07 & -0.222 & $0.086 * * *$ & 0.098 \\
\hline Stock returns & -0.020 & -0.317 & $0.942 * * *$ & -4.438 & $-0.571 * * *$ & 0.13 \\
\hline Interest rates & $-0.005^{* *}$ & -0.018 & 0.051 & $0.799 * * *$ & 0.002 & -0.063 \\
\hline VIX & 0.025 & 0.377 & $-0.429 * * *$ & 2.704 & $1.286 * * *$ & -0.202 \\
\hline Open interest & -0.010 & 0.063 & 0.029 & -0.884 & 0.004 & $1.048 * * *$ \\
\hline
\end{tabular}

Notes: Estimated effects following 1\% shocks, based on the estimated structural VAR model over the period 1 January 2001 - 19 October 2012 excluding the period 1 July $2008-31$ December 2008 . ***, ** and * denote significance at the $1 \%, 5 \%$ and $10 \%$ levels. 


\section{Appendix: Outline of the IH estimation methodology}

The method of identification through heteroskedasticity has been described in various articles. The original contribution was Rigobon (2003) who provides a proof of identification for a bivariate system. Further outlines can be found in Grisse (2010) and Ehrmann et al. (2011). A discussion of how these results relate to a maximum likelihood framework can be found in Lanne and Lütkepohl (2008). Here we restate the methodological issues involved for convenience.

Consider the structural VAR model

$$
A y_{t}=\tilde{c}+\tilde{A}_{1} y_{t-1}+\cdots+\tilde{A}_{p} y_{p-1}+\tilde{\Gamma} x_{t}+\varepsilon_{t}
$$

Where $y_{t}$ denotes a $n \times 1$ vector of endogenous variables, $x_{t}$ a $k \times 1$ vector of exogenous variables, $A$ is the $n \times n$ matrix of contemporaneous coefficients, the symbols with tilde $\tilde{A}_{i}, i=1, \ldots, p$ and $\tilde{\Gamma}$ denote the coefficient matrices on lagged values of the endogenous variables and on the exogenous variables, respectively, and $\varepsilon_{t}$ is the $n \times 1$ vector of structural shocks with diagonal covariance matrix $\Sigma_{\varepsilon}=E\left(\varepsilon_{t} \varepsilon_{t}{ }^{\prime}\right)$ so that $\varepsilon_{t} \sim \operatorname{iid}\left(0, \Sigma_{\varepsilon}\right)$.

The reduced form of (A1) is obtained by multiplication of $A^{-1}$ :

$$
y_{t}=c+A_{1} y_{t-1}+\cdots+A_{p} y_{p-1}+\Gamma x_{t}+u_{t}
$$

with the reduced-form coefficient matrices $A_{i}=A^{-1} \tilde{A}_{i}, i=1, \ldots, p, \Gamma=A^{-1} \tilde{\Gamma}$, and the reduced form errors $u_{t}=A^{-1} \varepsilon_{t}$ which are distributed as $u_{t} \sim\left(0, \Sigma_{u}\right)$ with $\Sigma_{u}=A^{-1} \Sigma_{\varepsilon} A^{-1}$.

The standard VAR methodology consists in estimating the reduced form coefficients and decomposing the associated estimated reduced-form residual covariance matrix into the elements of $A$ and $\Sigma_{\varepsilon}$ according to

$$
\widehat{\Sigma}_{u}=\hat{A}^{-1} \widehat{\Sigma}_{\varepsilon} \hat{A}^{-1^{\prime}}
$$

Since $\hat{\Sigma}_{u}$ is a symmetric matrix, the matrix equation (A3) embodies $n(n+1) / 2$ distinct scalar equations. If $A$ and $\Sigma_{\varepsilon}$ are unrestricted, we have $2 n^{2}$ parameters to estimate. In our application we restrict the diagonal elements of $A$ to be equal to one and $\Sigma_{\varepsilon}$ to be a diagonal matrix which reduces the number of parameters to $n^{2}$. Since this number still exceeds the number of equations, the traditional approach in structural VAR modeling has been to impose additional restrictions on the system, mainly by resorting to restrictions implied by economic theory.

An alternative approach is to use additional information about the data generating process to add equations to the system. Suppose that the structural shocks exhibit heteroskedasticity in that there are two distinct volatility regimes $\Sigma_{\varepsilon, 1}$ and $\Sigma_{\varepsilon, 2}$. Within each of these regimes structural shocks are homoscedastic but the volatility of shocks differs across regimes. Then our system of equations grows to

$$
\operatorname{vech}\left(\widehat{\Sigma}_{u, 1}\right)=\operatorname{vech}\left(\hat{A}^{-1} \widehat{\Sigma}_{\varepsilon, 1} \hat{A}^{-1^{\prime}}\right)
$$




$$
\operatorname{vech}\left(\widehat{\Sigma}_{u, 2}\right)=\operatorname{vech}\left(\hat{A}^{-1} \widehat{\Sigma}_{\varepsilon, 2} \hat{A}^{-1^{\prime}}\right)
$$

which now contains $n(n+1)$ equations. Under our setup, this equals the number of free parameters in $A, \Sigma_{\varepsilon, 1}$ and $\Sigma_{\varepsilon, 2}$. Consequently, the order condition of (exact) identification is fulfilled. With more regimes the system becomes overidentified. With $s$ volatility regimes, the only requirement that the different structural shock covariance matrices have to satisfy is that they not be multiples of each other, i.e. $\Sigma_{\varepsilon, i} \neq \mathrm{h} \cdot \Sigma_{\varepsilon, j}$ for $\mathrm{i} \neq \mathrm{j}, \mathrm{i}, \mathrm{j}=1, \ldots, \mathrm{s}$, and any non-negative scalar $h$.

If different volatility regimes are visible from the data or can be otherwise justified, the standard structural VAR approach suffers from misspecification. In such a situation, identification through heteroskedasticity solves the misspecification and at the same time dispenses with the need to impose restrictions on the parameters of interest. 